\title{
Investigation of the impact of roof configurations on the wind and thermal environment in football stadiums in hot climates
}

\author{
Sam Bonser ${ }^{\mathrm{a}, b^{*}}$, B.R. Hughes ${ }^{\mathrm{c}}$ and J.K. Calautit ${ }^{\mathrm{a}^{*}}$
}

${ }^{a}$ Department of Architecture and Build Environment, University of Nottingham NG7 2RD, UK; ${ }^{\mathrm{b}}$ Arup, City Gate West, Nottingham NG1 5AT, UK; ${ }^{\mathrm{c}}$ Department of

Mechanical Engineering, University of Stratchlyde G1 1XQ, UK

*Correspondingauthor:sam.bonser@arup.com,john.calautit1@nottingham.ac.uk

he present study provides an analysis of existing literature encompassing the wind and thermal analysis of football stadia, and how both can be manipulated through the modification of roof geometry. It introduces the potential for cooling strategies to create an internal environment capable of hosting elite-level international football in a hot climate. The motivation for the study stems from an absence of existing literature focussing on thermal flow in hot conditions for stadia and the requirement to investigate the hosting capabilities of Qatar for the 2022 FIFA World Cup. Stadium design plays a crucial role in determining the success of the tournament not only through the month-long event, but also with the legacy it leaves afterwards. To carry out the analysis, Computational Fluid Dynamics (CFD) simulations were conducted in an effort to produce internal conditions that satisfy official FIFA guidelines on optimal playing conditions in terms of wind and temperature distribution. These are ran on a model validated against existing literature to ensure accuracy, but considering the potential for error between model generations. The conclusions drawn suggest that a downward-pitched, large-radius retractable roof subsidised by the introduction of a mechanical system to create a cooling strategy reduces the external temperature down to $23^{\circ} \mathrm{C}$, with wind velocities not exceeding $4 \mathrm{~m} / \mathrm{s}$. Reinforced by results, these desired playing conditions can be achieved by closing the roof to 
precondition the stadium before an event, with the roof then retracted to ensure compliance with FIFA guidelines. The results from the present study can be a component in achieving a sustained positive legacy for the upcoming FIFA World Cup.

Keywords: building; Qatar2022; stadium; temperature; ventilation; wind

\section{Introduction}

The 2022 FIFA World Cup, scheduled to be hosted in Qatar between 21st November and 18th December (FIFA, 2017), is a prominent and controversial topic widely discussed beyond the footballing world. A tournament often headlining for sport and social reasons, the appointment to the Qatari Football Association on 2010 caused widespread criticism against the governing body FIFA (Web Archive, 2009). However, despite the negativity surrounding the appointment, preparation for the tournament continues. The design and construction of stadia is one of the primary sources of controversy, with arguments revolving around the hot/humid climate of the region and the lack of existing footballing infrastructure with the calibre or capability to host such a prestigious event. Therefore, it is of vital importance to the parties tasked with the designing of the new stadia to appreciate and overcome such difficulties. Two specific areas of design can be targeted for further analysis through literature review and subsequent investigation; roof geometry optimisation to provide peak wind and thermal conditions inside the stadium, and the evaluation of cooling solution to supplement the thermal conditions necessary for a successful tournament. The aim of the present study is to research the difficulties associated with stadium design in the context of climate, before investigating potential solutions to provide adequate wind and thermal conditions for elite-level performance. This study will conduct a review of existing studies of roof geometry optimisation, current FIFA stadium design specifications to establish the 
necessary design criteria, the current and predicted climate of the region, and current cooling solutions operating in identical or similar climates in urban semi-outdoor environments. A computational CFD model will be developed using the knowledge acquired from previous works of an existing stadium for the prediction of air flow patterns and thermal conditions. The computational model will be verified using grid sensitivity analysis and validated using previous works' experimental data. The impact of roof geometry and cooling systems on the airflow and temperature distribution will also be investigated. The difficulties faced regarding the legacy of the competition will be challenged by working to the task of year-round operation of the stadium.

\section{Previous related works}

A joint study by the Universities of Sheffield and Qatar (Sofotasiou, Hughes, \& Ghani, 2017) investigated "the parameters that determine the wind comfort in a twodimensional stadium model." The study comprised of two separate geometry optimisations; symmetric and asymmetric terraces. The results yielded after the optimisation process found that a $57 \%$ decrease in height and $835 \%$ increase in roof radius contributed "to a maximum velocity reduction of up to $26.5 \%$ " for a symmetric roof layout, and an $11.4 \mathrm{~m}$ height difference between terraces reduced the maximum velocity by $75 \%$. The work suggested that an asymmetrical roof structure had the greatest reduction in wind velocity, however the suitability of such a layout required greater understanding of the Qatari climate.

Described as a "dry, hot climate with low annual rainfall" (Ghani, Bialy, Bakochristou, Gamaledin, Rashwan, \& Hughes, 2017), Qatar is a low desert with a large temperature fluctuation between day and night. For a tournament occurring in November-December, the average temperature is $23.5^{\circ} \mathrm{C}$ (Calautit, Hughes, \& Nasir, 2017) and yet only 
$0.4 \mathrm{~mm}$ of rainfall. The high humidity reduces saturation capabilities of air conditioning systems (Moosavi, Zandi, \& Bidi, 2018), and the low rainfall levels and desert location determine a lack of water sourcing for cooling purposes, reducing the feasibility of using water-based cooling strategies, such as mist cooling (Yao, Costanzo, Li, Zhang, \& Li, 2018).

Whilst an experienced temperature of $23.5^{\circ} \mathrm{C}$ is an acceptable environment to facilitate maximum performance of elite athletes (Beaard, 2013), the legacy of the competition is threatened by the inability for use of a stadium between April and October; a result of the average temperature consistently exceeding $30^{\circ} \mathrm{C}$ (Ghani et al., 2017). Therefore, the combination of a high mean temperature and semi-outdoor environment required further investigation into cooling solutions capable for such a climate and function with the goal of creating a successful legacy of the 2022 FIFA World Cup.

Hotel Park in Doha, Qatar is an Arup project that aimed to use passive cooling strategies to provide a tranquil open space outdoors. Natural shading provided by trees and foliage, combined with public pools and fountains reduced the environment by $10^{\circ} \mathrm{C}$ compared to the city. The use of natural shading, however, must be adapted for stadium design. With the findings of the roof optimisation study (Sofotasiou et al., 2017) suggesting a smaller terrace reduces the wind velocities inside the stadium bowl, a preliminary conclusion is drawn to hypothesise that a larger terrace will encourage wind velocities to be used as a form of natural ventilation whilst providing increased levels of shading to the pitch. Qatar's average windspeed of 8mph (Ghani et al., 2017) $(3.6 \mathrm{~m} / \mathrm{s})$ suggests that natural ventilation is a viable solution but would result in a high Reynold's number and hence yield unpredictable, turbulent wind patterns. Therefore, a balance between roof geometry and terrace height must be sought to optimise the wind velocity in the context of cooling whilst providing sufficient shading from direct 
sunlight.

Focussing on the roof geometry, the decrease in terrace height requires a greater surface area of roof to counteract the increased solar gains through the oculus opening.

Additionally, encouraging or introducing natural ventilation to supplement the cooling effects of increasing the roof geometry provides an increased timespan of usability of the stadium. Ideally, the roof would span the entire stadium and create an indoor environment which would allow much more accurate climate control. The precedent for such an idea lies in two areas; an existing study into closed roof stadia for cooling effects in Qatar (Arup, 2017), and existing stadia operating with a retractable roof for elite-level football.

The Qatar Showcase (Arup, 2017) was an Arup Associates' project aiming to create an indoor stadium environment that contained sufficient ventilation to provide thermal conditions adequate to host elite-level football. Utilising solar PV panels, absorption chillers and eutectic storage tanks, the design also contains a rotating geodesic dome (Figure 1), that when closed creates an indoor environment cooled by localised natural ventilation through vents underneath the spectator's seats. At night, the dome swivels $180 \mathrm{o}$, and in conjunction with an opening façade, exposes the pitch to the outdoor environment as a form of night cooling.
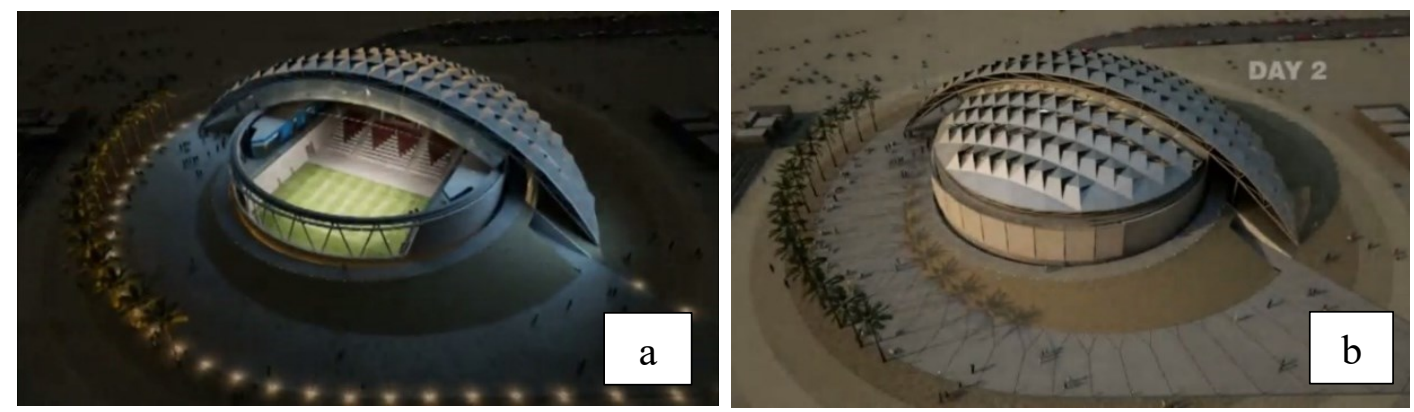

Figure 1. Closed (a) and open (b) geodesic roof for the Arup Associates Qatar Showcase stadium (Arup, 2017). 
The primary difficulties experienced with this model revolve around scale. The occupancy of the Qatar Showcase is 500 spectators, and hence increasing the occupancy to the actual numbers i.e. 60,000 will drastically increase both the space and cooling system requirements. The model achieved an indoor temperature of $23^{\circ} \mathrm{C}$ despite a $45^{\circ} \mathrm{C}$ external temperature, but the cooling effect of the ventilation is severely disrupted on a windy day. "The danger is that when [the wind] hits the rim of the stadium's top tier of seating, it will create currents that scour out the reservoir of cool air in the bowl" (Kennett, 2017). The challenge that can be deduced from this existing project, therefore, is to limit the wind from impacting the interior of the stadium should mechanical ventilation be used. The wind velocities experienced inside the stadium bowl can be used as a form of natural ventilation (Sofotasiou et al., 2017), but any interference with external wind will remove any colder air generated inside the stadium (Kennett, 2017). To further understand potential solutions for these criteria, the use of a retractable roof was explored.

Either to be used in conjunction with Arup Associates' findings or as a separate solution, investigating the precedent for retractable roofs in elite football can provide an effective method of nullifying the solar heat gains experienced on the pitch, whilst also creating further design conditions regarding roof geometry. The 2006 World Cup in Germany contained a stadium with a retractable roof, the Veltins Arena in Gelsenkirchen. As "World Cup matches cannot be played under cover” (Kennett, 2017), the roof was retracted thirty minutes before kick-off having been fully closed beforehand. The primary disadvantage to having a permanently closed roof other than during a match is the lack of sunlight and $\mathrm{CO} 2$ required to stimulate grass growth for the playing surface. The Veltins Arena utilises a sliding pitch that is withdrawn underneath a terrace to the outdoors. This therefore does not compromise the internal, 
mechanically generated climate whilst ensuring sufficient grass quality. An alternative solution would be the use of artificial turf, which would reduce the requirement for watering with the aforementioned water-sourcing issues. The 2015 Women's World Cup in Canada solely used artificial turf, and hence provided a precedent for the use in elite football.

In the context of roof geometry, it was understood that a retractable roof was a viable structure against FIFA's stadium criteria. Therefore, the modelling of wind and thermal analysis of both an enclosed and open roof could be conducted, with the results compared to determine a preferred solution. The difficulty with stadium modelling, however, lies with the high possibility of an inaccurate model. To overcome this issue, an existing stadium was modelled to yield a set of results to compare to other studies. The Amsterdam ArenA in the Netherlands "represents a simplified version of a benchmark arena design that is widely used in literature studies" (Sofotasiou, Hughes, \& Calautit, 2015), and therefore existing simulation data was compared to the data produced in the present study via CFD to validate the model.

The study (Van Hooff \& Blocken, 2013) focused largely on monitoring the Carbon Dioxide (CO2) levels inside the Amsterdam ArenA during summer concerts. Despite the differing functions of the stadium between the study and the present work resulting in no relevant conclusions to be used as model validation, the extensive analysis into the modelling of the Amsterdam ArenA with regards to CFD was used as a guideline alongside additional works.

The work of (Van Hooff \& Blocken, 2010a) offered a higher quantity of relevant discussion points, this time revolving around the use of natural ventilation in the stadium. It highlighted the absence of a heating, ventilation and air-conditioning 
(HVAC) system, and so monitored the air-changes per hour $(\mathrm{ACH})$ inside the stadium and offered alternative natural ventilation strategies to counteract the insufficient ventilation and overheating being experienced within the stadium (Figure 2).

Subsequently, CFD was used to simulate the effectiveness of the alternative natural ventilation strategies against the current configuration, with the results shown in Table 1.
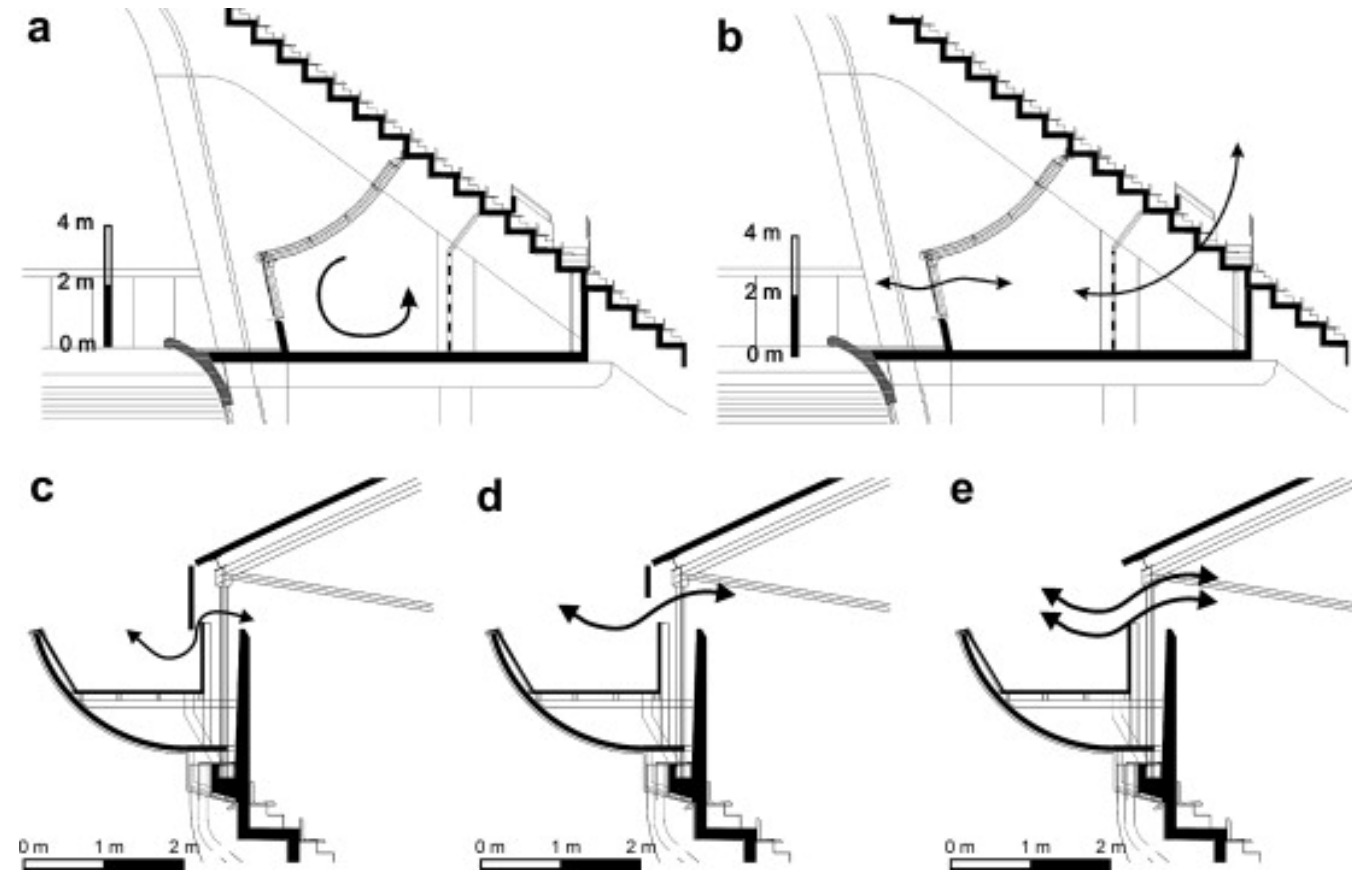

d

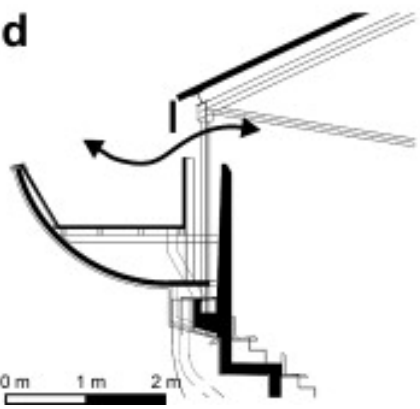

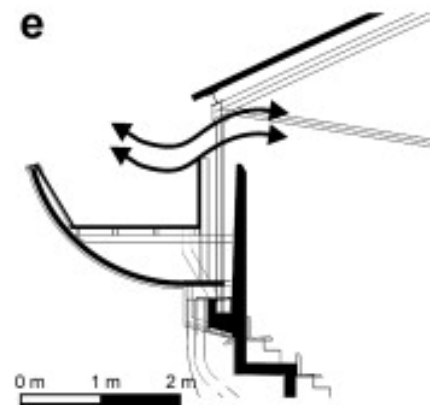

Figure 2. (a,c) the current ventilation configuration; (b) alternative strategy 1; (d) alternative strategy 2; (e) alternative strategy 3. Strategy 4 is a fully opened roof (Van Hooff \& Blocken, 2010a).

Table 1. The ACH values achieved for the 5 different ventilation strategies, with a reference wind velocity, $\mathrm{U}_{10}=5 \mathrm{~m} / \mathrm{s}$ and a fixed indoor surface temperature (Van Hooff \& Blocken, 2010a).

\begin{tabular}{|c|c|c|c|c|c|}
\hline \multirow{2}{*}{$\begin{array}{l}\text { Ventilation configuration } \\
\qquad \varnothing\left(^{\circ}\right)(\text { Wind Direction) }\end{array}$} & \multicolumn{5}{|c|}{$\operatorname{ACH}\left(h^{-1}\right)$} \\
\hline & $16^{\circ}$ & $151^{\circ}$ & $196^{\circ}$ & $331^{\circ}$ & Average \\
\hline Current & 1.51 & 1.33 & 1.11 & 1.49 & 1.36 \\
\hline Alternative strategy 1 & 1.56 & 1.52 & 1.12 & 1.33 & 1.38 \\
\hline Alternative strategy 2 & 1.91 & 1.61 & 1.29 & 1.54 & 1.59 \\
\hline
\end{tabular}




\begin{tabular}{llllll}
\hline Alternative strategy 3 & 2.19 & 2.28 & 1.61 & 1.72 & 1.95 \\
\hline Alternative strategy 4 & 4.57 & 3.40 & 2.66 & 3.41 & 3.51 \\
\hline
\end{tabular}

The aforementioned design criteria suggest that the high ACH with strategy 4 would only replace the cool interior air, and so only the current strategy was used for model validation. The remaining results can subsequently be used as further research into enhancing the cooling effects inside the stadium.

It can be concluded from the literature review that extensive research has already been conducted into the ventilation of a stadium bowl. The depth of these studies suggest further research into this area will not contribute additional knowledge. However, no work has investigated the impact of roof geometry optimisation on the thermal flow patterns in a stadium in a hot climate, and so the combination of the studies supplemented by research into thermal conditions will provide informative and innovative conclusions towards the legacy issues of stadium design in this climate. With the aforementioned gap, any subsequent modifications to stadium geometry and/or cooling systems are unprecedented in the immediate context. This allows a wide berth for research into both these categories in an effort to enhance the capabilities of stadia.

\section{Methodology}

Following the review of existing literature, a regimented methodology was established. This ensured only correct and useful processes were undertaken. The first stage of the present study was to create a benchmark validated model of a stadium (Van Hooff \& Blocken, 2010b). Once a preliminary simulation on the model had been conducted, the results were compared to the previous work results to ensure an accurate stadium model. From there, the model was adapted to the climate of Qatar and an initial estimation of the operating conditions of the stadium was simulated. After completion, 
the roof oculus opening was removed to simulate a closed roof scenario, with air conditioning jets sized to provide adequate conditions within the stadium. Subsequently, the effects of opening the roof was investigated, with the conditions compared to those of the closed roof scenario. From there, the roof geometry and cooling jet inlet velocity was optimised to offer the most successful method of climate control.

\subsection{D model geometry development}

A 3D model with a volume of $1.2 \times 10^{6} \mathrm{~m}^{3}$ of the benchmark stadium was created using SolidWorks software based on the dimensions in Figure 3a. The oval shaped stadium has a dome type roof which can be opened and closed depending on the weather and function. The stand has two separate tiers and runs along the full perimeter. The four black arrows on the plane schematic in Figure $3 \mathrm{~b}$ shows the locations of the four $41.5 \mathrm{~m}^{2}$ gates or openings connecting the external and internal environments. Each opening travels underneath the terracing to connect the inner logistics ring between the terraces and the pitch with the external environment. They function as the spectator entrances as well as a source of ventilation. The 3D model required a number of simplifications to reduce the computational time/resource; the lack of explicit seating on the terraces, the removal of outer components such as the roof exoskeleton, and the exclusion of any surrounding buildings all could reduce the accuracy of results yielded. The effects of the filleted corners on the exit of the openings will be determined after the preliminary results, with the wind flow path showing the impact, if any, the sharp edges had. The presence of the white roof frame seen in Figure 3a, which acts as the rail system for the retractable roof, made the cross-section mapping a difficult process as it masked the true end to the permanent roof structure. After creating the 3D model, it was then imported into ANSYS Workbench and DesignModeler to develop a computational domain encapsulating the model and acting as the stadium microclimate (Cook, Ji, \& Hunt, 
2003; Jiru, \& Bitsuamlak, 2010).
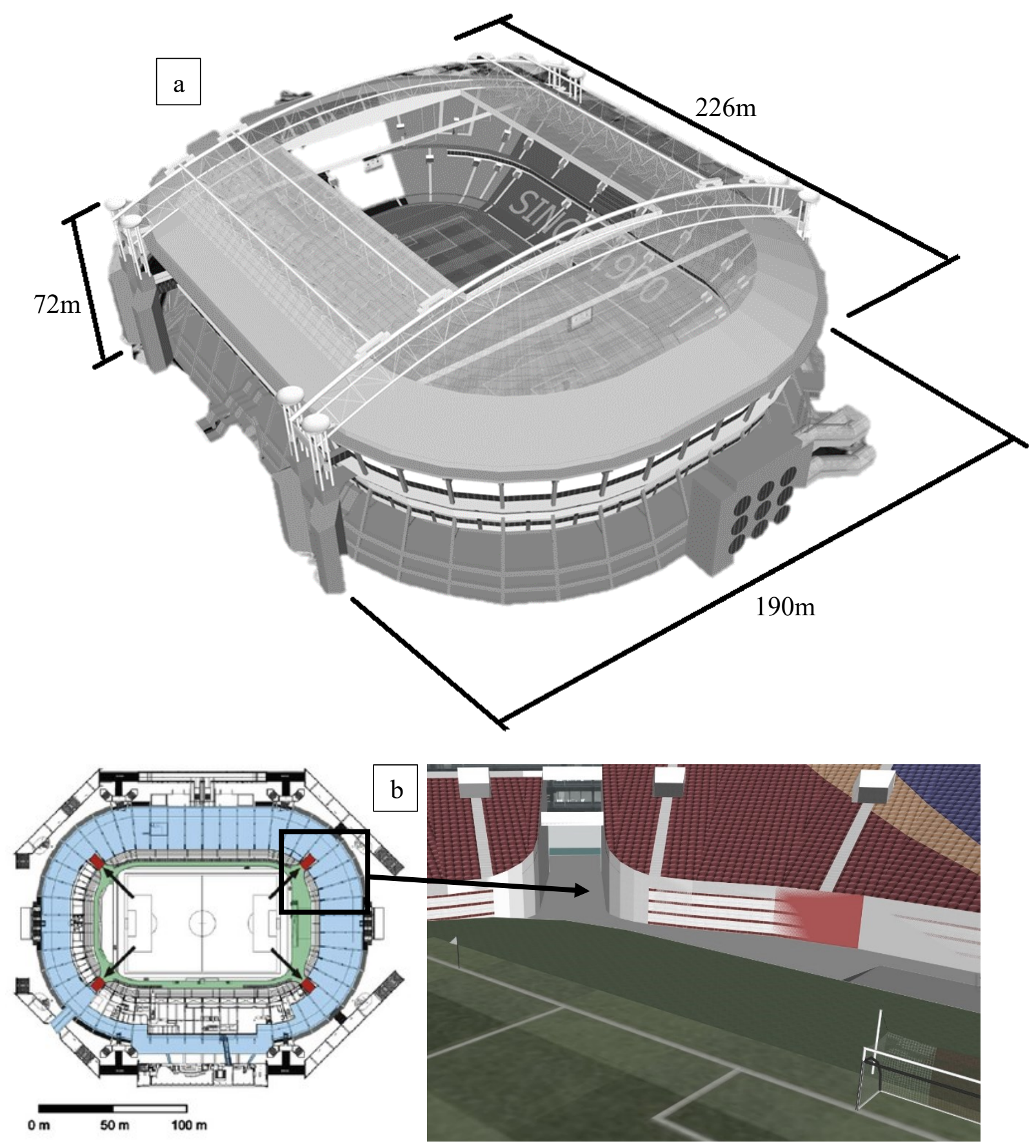

Figure 3. (a) Schematic 3D diagram of the stadium with main dimensions in metres, adapted from Abel T (b) location of the gates or openings (Van Hooff \& Blocken, 2010b).

\subsection{Boundary conditions}

A rectangular $2900 \mathrm{~m} \times 2900 \mathrm{~m} \times 908.5 \mathrm{~m}$ computational domain was created around the 
stadium geometry as shown in Figure 4 following best practice guidelines (Cowan, Castro, \& Robins, 1997; Tominaga, et al. 2008), which recommended distances of at least $5 \mathrm{H}$ from the stadium to the to the inlet, top and sides of the domain and $15 \mathrm{H}$ to the outlet. $\quad$ Logarithmic wind speed profile

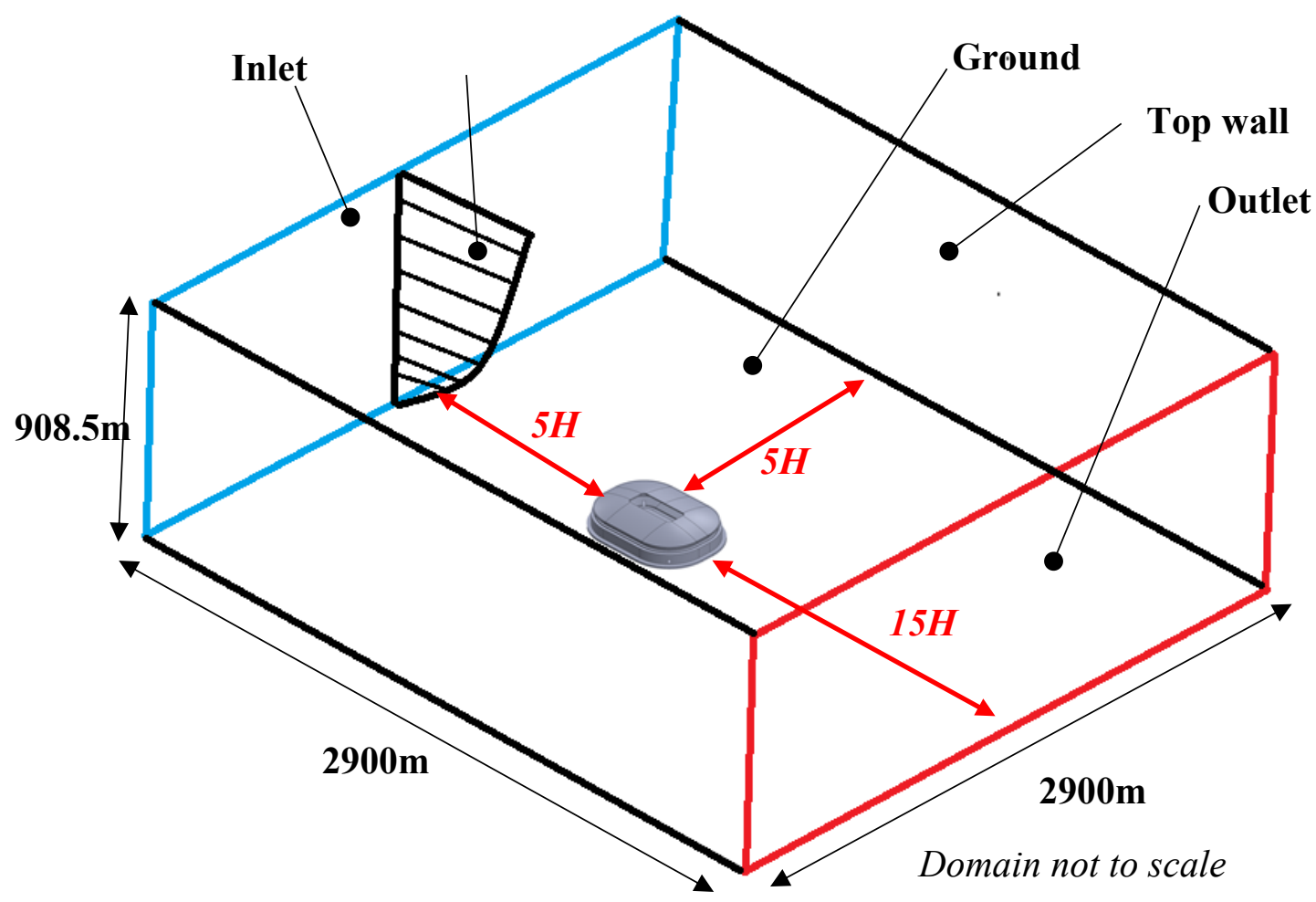

Figure 4. Computational domain and boundary conditions.

Based on (Van Hooff \& Blocken, 2010b), the reference wind velocity experienced in the location was set as $\mathrm{U}_{10}=5 \mathrm{~m} / \mathrm{s}$, with an exponential relationship with the height above ground defined by $U=U_{10} \cdot \ln \left(\frac{h}{z_{0}}\right) / \ln \left(\frac{10}{z_{0}}\right)$, where $U(\mathrm{~m} / \mathrm{s})$ is the wind velocity at height $h(\mathrm{~m})$ and $z_{o}(\mathrm{~m})$ is the aerodynamic roughness length $(0.5 \mathrm{~m})$. With the obtained wind velocity values up to the domain height of $908.5 \mathrm{~m}$, the turbulent model could be defined. The study also assumed the $k-\varepsilon$ turbulence model (Richards \& Hoxey, 1993; Mochida, Tominaga, Murakami, Yoshie, Ishihara, \& Ooka, 2002).: 
- $\quad k=1.5 \cdot I_{U} \cdot U^{2}$, where $k(\mathrm{~J} / \mathrm{kg})$ is the turbulent kinetic energy, $\mathrm{IU}_{\mathrm{U}}(\%)$ is the turbulent intensity ranging from $30 \%$ at pedestrian height $(2 \mathrm{~m})$ to $5 \%$ at gradient height and $U(\mathrm{~m} / \mathrm{s})$ is the calculated wind velocity

- $\varepsilon=U_{A B L}{ }^{* 3} / K(h+10)$, where $\varepsilon(\mathrm{J} / \mathrm{kg} . \mathrm{s})$ is the turbulence dissipation rate, $U_{A B L}{ }^{*}(\mathrm{~m} / \mathrm{s})$ is the atmospheric boundary layer friction velocity, $K$ is the von Karman constant (0.42) and $h(\mathrm{~m})$ is the height (Blocken, Stathopoulos, \& Carmeliet, 2007).

These three components created the necessary profiles and were used as the inlet conditions for the four wind directions shown in Table 1. For the ground surface, aerodynamic roughness length was set to $0.03 \mathrm{~m}$, which was imposed in Fluent by setting equivalent sand-grain roughness height to $0.59 \mathrm{~m}$ and roughness constant to 0.5 . It should be noted that the values used were estimated based on observation of the surrounding terrain and the Davenport roughness classification for an upstream fetch of about $10 \mathrm{~km}$. The building surfaces were set to have zero roughness height (Van Hooff \& Blocken, 2010b). Zero static pressure is imposed at the outlet. The top wall was set as a slip wall with zero normal velocity and gradients of all variables.

For the simulation of the stadium in hot climate conditions, per ASHRAE design data (ASHRAE, 2005), the maximum dry-bulb air temperature is $43.2^{\circ} \mathrm{C}\left(316.35^{\circ} \mathrm{K}\right)$ as a $0.4 \%$ peak condition, which was set as the temperature of air at the inlet to represent the extreme weather condition as well as yielding a worst-case set of results. The same source suggested a $6.5 \mathrm{~m} / \mathrm{s}$ and $350^{\circ}$ mean coincident wind speed and direction, both recorded at $10 \mathrm{~m}$ above sea level. As temperature was the fundamental parameter for the Qatar simulations, cooling jets were installed inside the stadium at an initial velocity of $5 \mathrm{~m} / \mathrm{s}$ and at $23^{\circ} \mathrm{C}$ (Ghani et al., 2017; Beaard, 2013), with the location shown in Figure 5. As cooling load also wasn't a considered parameter at this stage, the jets weren't sized for 
efficiency but to determine the effect on the temperature inside the stadium bowl. The cooling jets had a total area of $122.6 \mathrm{~m}^{2}$ and were placed to allow the Coanda effect (the use of a flat surface to distribute air further into a space) to provide ample mixing and a reduction in air stratification.

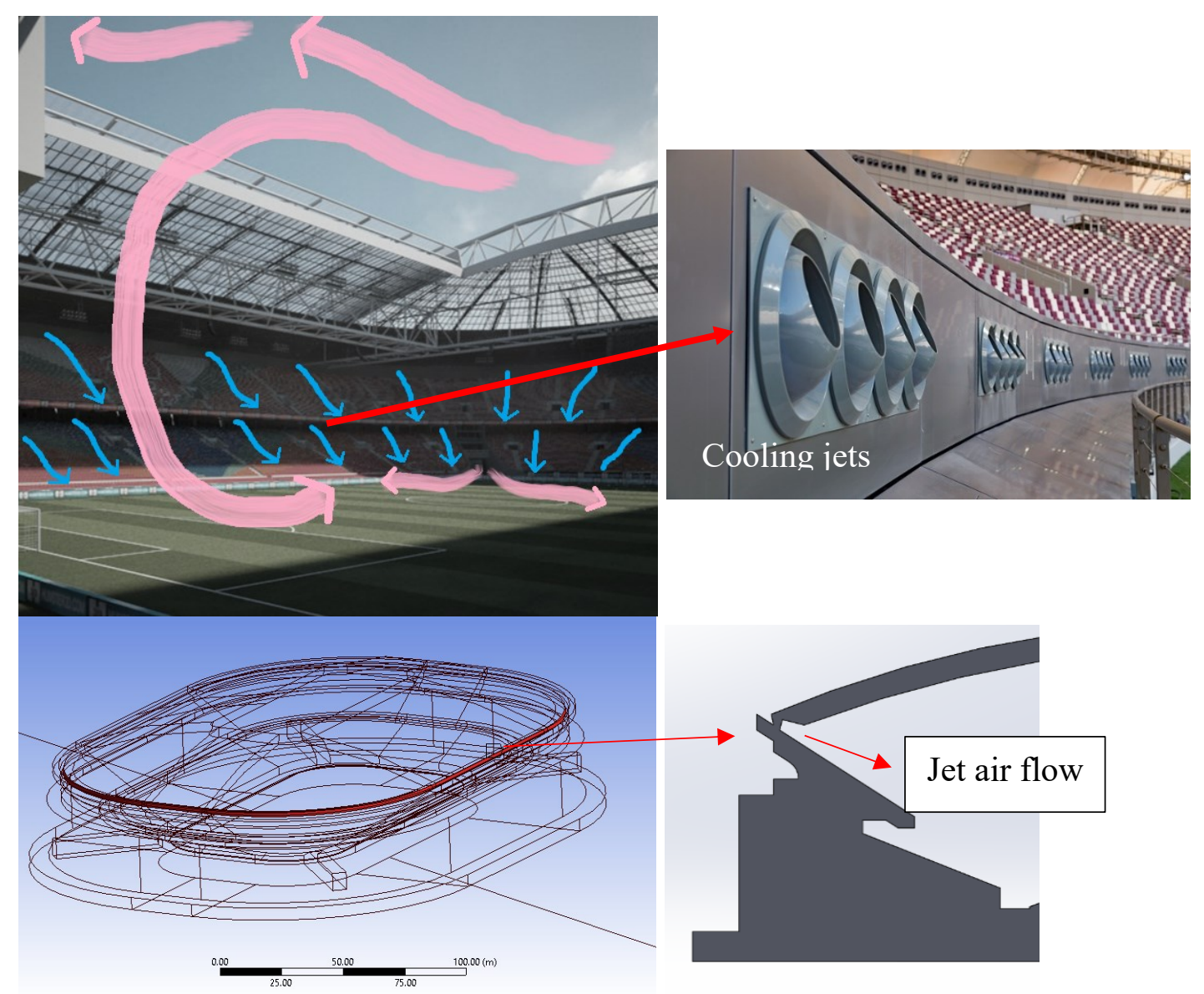

Figure 5. Cooling jets location in the stadium model.

\subsection{Mesh generation and sensitivity analysis}

This study reinforced the primary risks that simulations encounter; the high scale grids and meshes required to satisfy the small openings require a large amount of computational power and time. However, the meshing process for the study used a body-fitted grid for both the "solid and fluid parts", suggesting both the domain and the stadium. This largely increases the number of calculations being run per iteration, and hence results in a longer process. The mesh quality in the immediate vicinity of the 
stadium is very important for the accurate simulation of the flows (Van Hooff \& Blocken, 2010a). The computational domain was then subject to inflated mesh generation, seen in Figure 6. This allowed a program-controlled inflation strategy, ensuring the mesh sizing decreased around the stadium model in an effort to produce more accurate sets of data whilst ensuring large enough cells in non-vital regions to speed up the simulations (Gong\& Hang, 2018; Jiang, Allocca, \& Chen, 2004; Calautit \& Hughes, 2014a). Using a tetrahedral mesh structure of a maximum size of $64 \mathrm{~m}$ and a minimum size of $0.25 \mathrm{~m}, 1.48 \times 106$ cells were produced and the mesh was deemed satisfactory following a grid sensitivity analysis, which was performed by using three grids with different grid resolutions and by comparing relevant parameters (Chaudhry, Calautit, \& Hughes, 2015; Calautit \& Hughes, 2014b) at relevant locations i.e. ventilation rate through the gates.

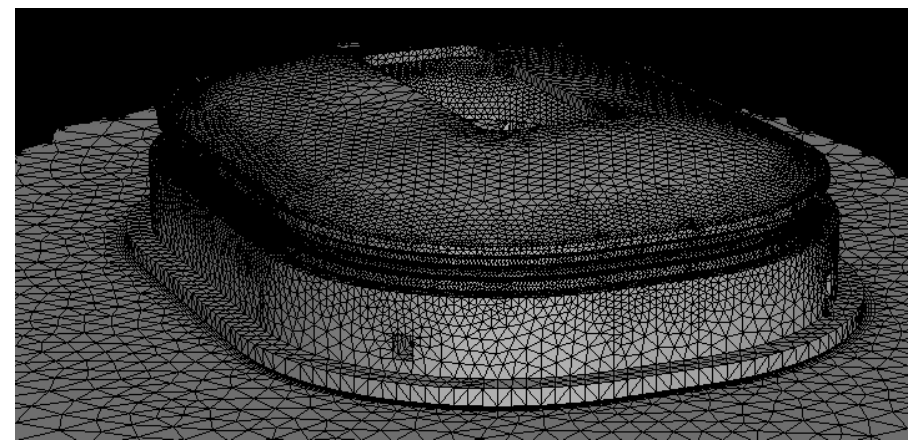

Figure 6. The inflated mesh surrounding the stadium model.

\subsection{CFD theory and solver settings}

The numerical simulations were carried out using ANSYS FLUENT 18 software. The assumptions for the steady state simulation comprised a three-dimensional, fullyturbulent, and incompressible flow. The turbulent nature of the flow was modelled by the standard $\mathrm{k}-\varepsilon$ model, which was chosen because of its overall good performance for wind flows around building and indoor flows (Van Hooff \& Blocken, 2010a, Van Hooff \& Blocken, 2010b). The CFD code used the Finite Volume Method (FVM) approach 
and employed the Semi-Implicit Method for Pressure-Linked Equations (SIMPLE) velocity-pressure coupling algorithm with the second order upwind discretisation. The simulations were completed using parallel processing on a workstation with two Intel Xeon 2.8GHz processor and 64GB Fully-buffered DDR2.

The governing equations for the 1-continuity, 2-momentum, 3-energy, 4-turbulent kinetic energy (TKE) and 5-energy dissipation rate are detailed below:

$$
\frac{\partial \rho}{\partial t}+\nabla \cdot(\rho u)=0
$$

where $\rho$ is density, t is time and $\mathrm{u}$ is fluid velocity vector.

$$
\frac{\partial \rho u}{\mathrm{~d} t}+\nabla \cdot(\rho u u)=-\nabla p+\rho g+\nabla \cdot(\mu \nabla u)-\nabla \cdot \tau_{t}
$$

where $\mathrm{p}$ is the pressure, $\mathrm{g}$ is vector of gravitational acceleration, $\mu$ is molecular dynamic viscosity and $\tau_{t}$ is the divergence of the turbulence stresses which accounts for auxiliary stresses due to velocity fluctuations.

$$
\frac{\partial(\rho \mathrm{e})}{\partial t}+\nabla \cdot(\rho \mathrm{e} u)=\nabla \cdot\left(k_{e f f} \nabla T\right)-\nabla \cdot\left(\sum_{i} h_{i} j_{i}\right)
$$

where $\mathrm{e}$ is the specific internal energy, $\mathrm{k}_{\mathrm{eff}}$ is the effective heat conductivity, $\mathrm{T}$ is the air temperature, hi is the specific enthalpy of fluid and $\mathrm{j}_{\mathrm{i}}$ is the mass flux.

$$
\begin{gathered}
\frac{\partial(\rho \mathrm{k})}{\partial t}+\nabla \cdot(\rho \mathrm{k} u)=\nabla \cdot\left[\alpha_{k} \mu_{e f f} \nabla \mathrm{k}\right]+G_{k}+G_{b}-\rho_{\varepsilon} \\
\frac{\partial(\rho \varepsilon)}{\partial t}+\nabla \cdot(\rho \varepsilon u)=\nabla \cdot\left[\alpha_{k} \mu_{e f f} \nabla \varepsilon\right]+C_{1 \varepsilon} \frac{\varepsilon}{k}\left(G_{k}+C_{3 \varepsilon} G_{b}\right)-C_{2 \varepsilon} \rho \frac{\varepsilon^{2}}{k}
\end{gathered}
$$


where $G_{k}$ is the source of TKE due to average velocity gradient, $G_{b}$ is the source of TKE

due to buoyancy force, ${ }^{\alpha_{k}}$ and $\alpha_{\varepsilon}$ are turbulent Prandtls numbers,,$C_{1 \varepsilon} C_{2 \varepsilon}$ and ${ }^{C_{3 \varepsilon}}$ are empirical model constants.

\subsection{Computational method validation}

A bounded plane was created at each of the five openings (four gate openings and the roof, Figure 7), with the area-weighted average wind velocity recorded for each of the four wind directions. The volumetric flow rate and air-changes per hour were calculated; $A C H=\dot{Q} \times 3600 / V$, where $\dot{Q}(\mathrm{~m} 3 / \mathrm{s})$ is the volumetric flow rate and $\mathrm{V}$ (m3) is the volume of the stadium. This yielded the set of results in Table 2, which also shows the comparison against the target results from (Van Hooff \& Blocken, 2010b).

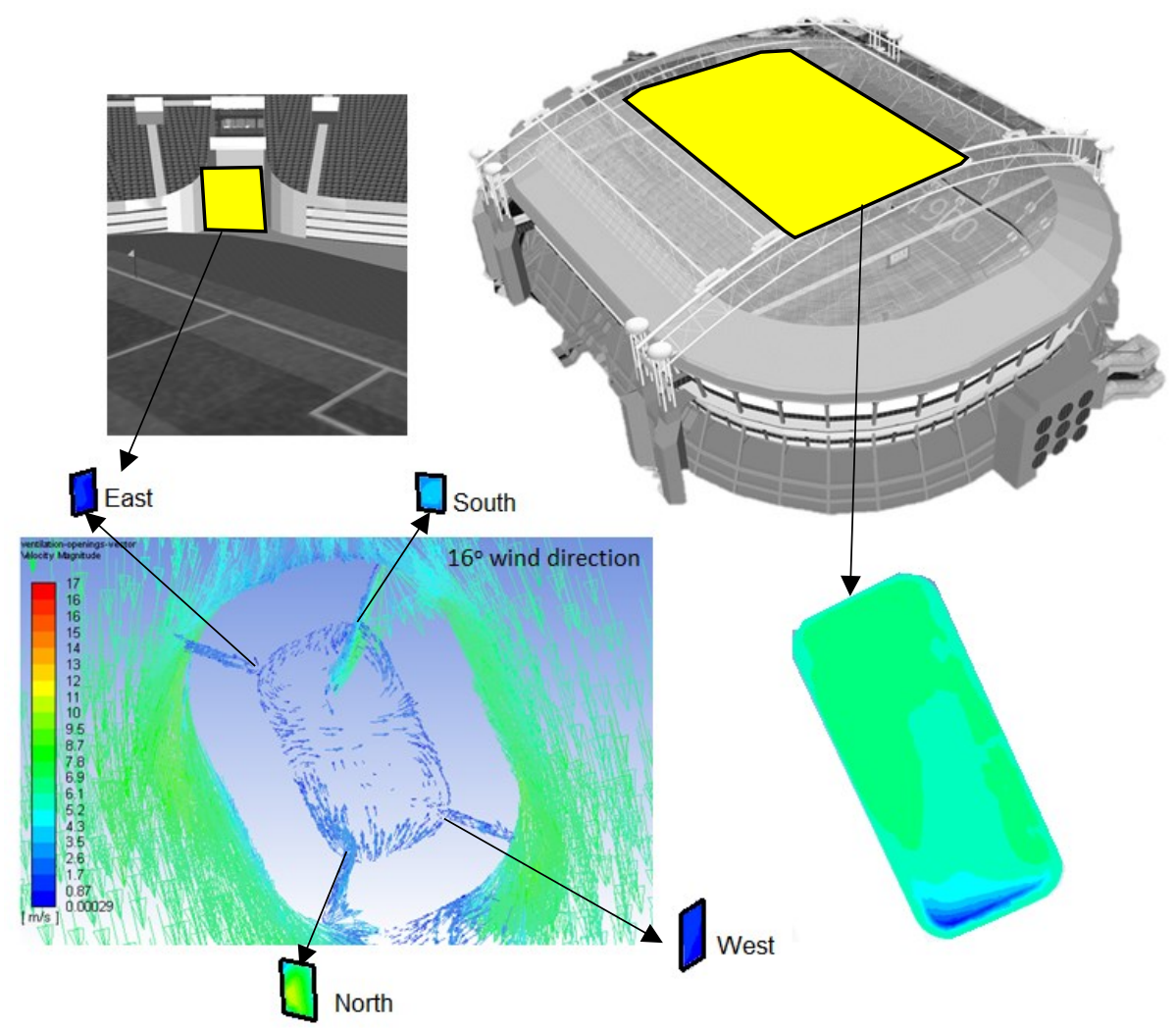

Figure 7. The plane creation at the ventilation opening inlet (left) and the resulting meshes of the four ventilation openings and the roof (right). 
Table 2. The calculated air change rates for each wind direction and opening, compared to the findings of (Van Hooff \& Blocken, 2010b).

\begin{tabular}{|c|c|c|c|c|c|}
\hline $\begin{array}{l}\text { Wind } \\
\text { direction }\left(^{\circ}\right)\end{array}$ & $\begin{array}{c}\text { Ventilation } \\
\text { opening }\end{array}$ & $\begin{array}{c}\text { Volumetric } \\
\text { flow rate }\left(\mathrm{m}^{3} / \mathrm{s}\right)\end{array}$ & $\operatorname{ACH}\left(h^{-1}\right)$ & $\begin{array}{c}\text { Current } \\
\text { Study ACH } \\
\left(\mathbf{h}^{-1}\right)\end{array}$ & $\begin{array}{c}\text { Validation ACH }\left(h^{-1}\right) \\
\text { (Van Hooff \& } \\
\text { Blocken, 2010b) }\end{array}$ \\
\hline \multirow{4}{*}{16} & North & 164.8 & 0.494 & \multirow{4}{*}{1.38} & \multirow{4}{*}{1.51} \\
\hline & East & 16.1 & 0.048 & & \\
\hline & South & 77.3 & 0.232 & & \\
\hline & Roof & 203.1 & 0.609 & & \\
\hline \multirow{2}{*}{151} & South & 247.3 & 0.742 & \multirow{2}{*}{1.24} & \multirow{2}{*}{1.33} \\
\hline & Roof & 166.7 & 0.500 & & \\
\hline \multirow{3}{*}{196} & North & 67.4 & 0.202 & \multirow{3}{*}{1.23} & \multirow{3}{*}{1.11} \\
\hline & South & 160.6 & 0.482 & & \\
\hline & Roof & 183.4 & 0.550 & & \\
\hline \multirow{4}{*}{331} & North & 253.1 & 0.759 & \multirow{3}{*}{1.48} & \multirow{3}{*}{1.49} \\
\hline & South & 39.5 & 0.119 & & \\
\hline & Roof & 199.6 & 0.599 & & \\
\hline & & & Average & 1.33 & 1.36 \\
\hline
\end{tabular}

Table 2 indicated that the ACH for the different wind directions weren't exact with the existing study findings, but the obtained average for the model has a margin of error of $1.9 \%$. Considering the aforementioned difference of the exclusion of the surrounding buildings, in combination with human error in the model creation, the findings deemed the stadium model successfully validated against existing studies. This was reinforced by comparing the results of different wind directions; the results for the non-obstructed directions were the most accurate.

\section{Results and discussions: Open roof stadium benchmark model}

In order to produce an initial estimate of the operating conditions of the stadium in the selected case study country of Qatar, the validated model achieved in Section 3 was subject to different climate conditions representing the potential weather experienced in the Qatari summer. The initial simulation ran with the weather conditions and jet 
velocities outlined in Sections 3.2. All other parameters, including geometry and mesh, remained identical to the validated model. Figures 8 and 9 indicate how the cooling jets were capable of creating a cooled environment inside the stadium bowl, but temperature fluctuations occur. The satisfactory $\sim 23^{\circ} \mathrm{C}$ covers the majority of the stadium interior, but a $44^{\circ} \mathrm{C}$ hotspot occurs through one of the openings. The warm air, driven by the northerly-prevailing wind, enters the stadium through the northern opening.

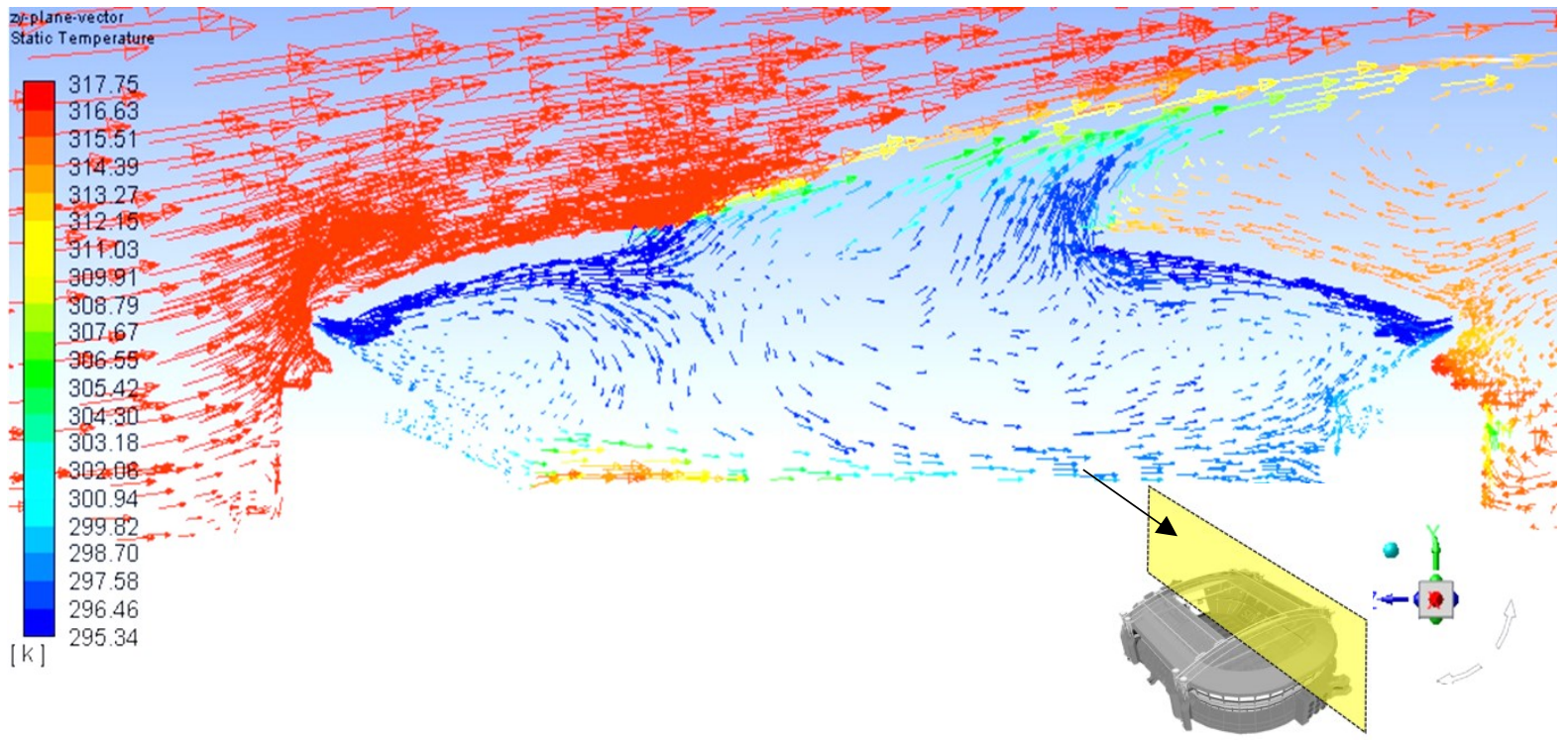

Figure 8. Cross-sectional temperature vector inside the benchmark stadium bowl (left to right wind direction).

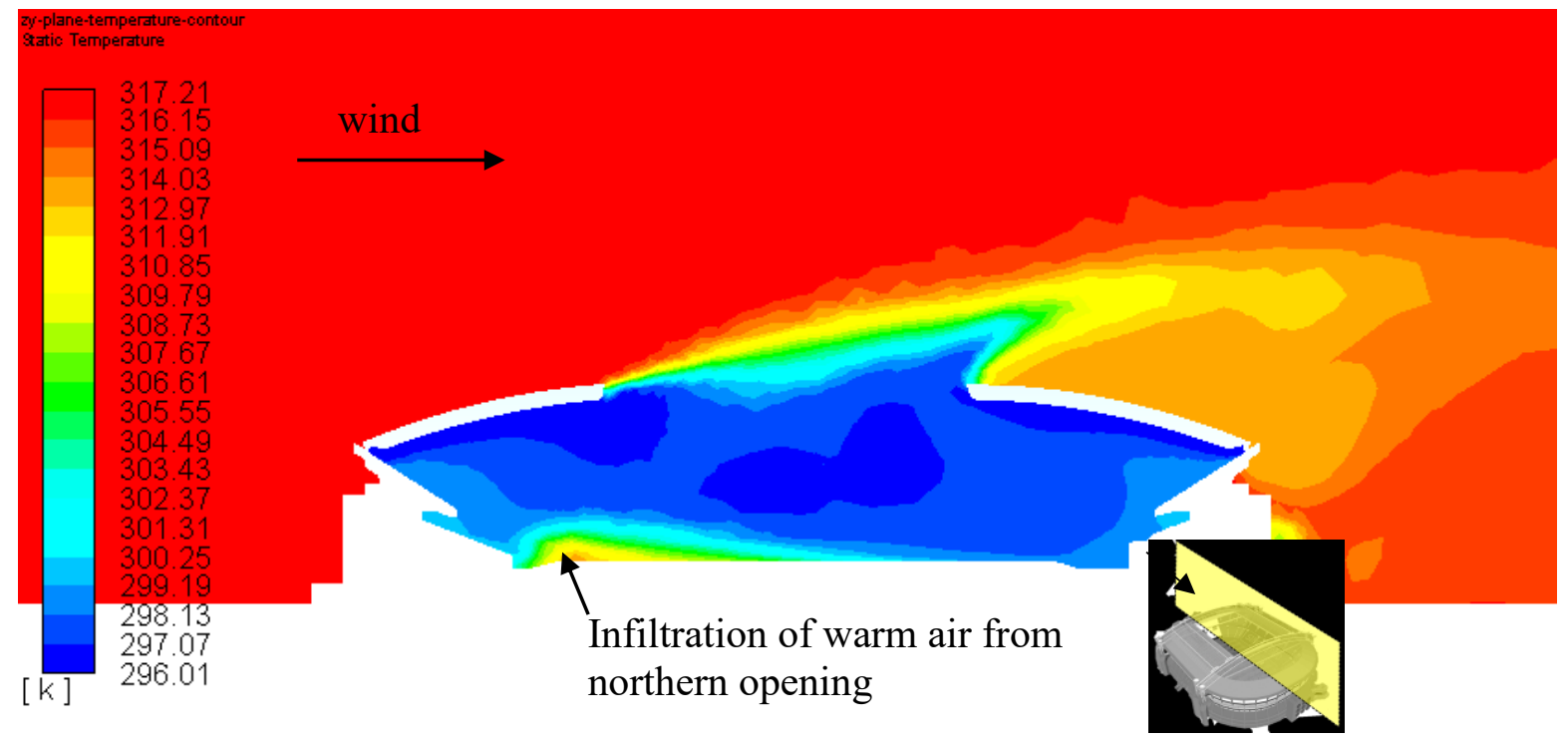


Figure 9. Cross-sectional temperature contour inside the stadium bowl (left to right wind direction).

The air flow through the roof oculus occurred in the desired direction; from indoor to outdoor, which prevents the majority of the internal environment from being impacted by the $44^{\circ} \mathrm{C}$ climate and can be attributed to the velocity of the cooling jets in combination with the Coanda effect. The plume of hot air at the ventilation opening, however, would cause severe discomfort for both spectators and players, and so the cooling jets inlet velocity was increased to $10 \mathrm{~m} / \mathrm{s}$ to determine the effectiveness.

Figure 10, when compared with Figure 9, showed that increasing the inlet velocity of the jets drastically reduced, but not removed, the heat plume experienced from the northern ventilation opening. The expulsion of colder air out of the roof oculus increases in magnitude, and hence a conclusion could be drawn stating that increasing the cooling jet velocity reduced the influx of hot air through the ventilation openings. However, increasing the wind velocity inside the stadium can lead towards potentially altering the results of the match being played and so caution must be taken to avoid this possibility. High wind velocities (Table 3 (Shi \& An, 2017)) can cause significant ball displacement during open play, in rare cases leading to goals without the input of the benefitting team and to no fault of the penalised team. In an elite level international tournament, an occurrence of such an event would cause widespread negative publicity in combination with further scrutiny placed on the Qatar's hosting capabilities. 


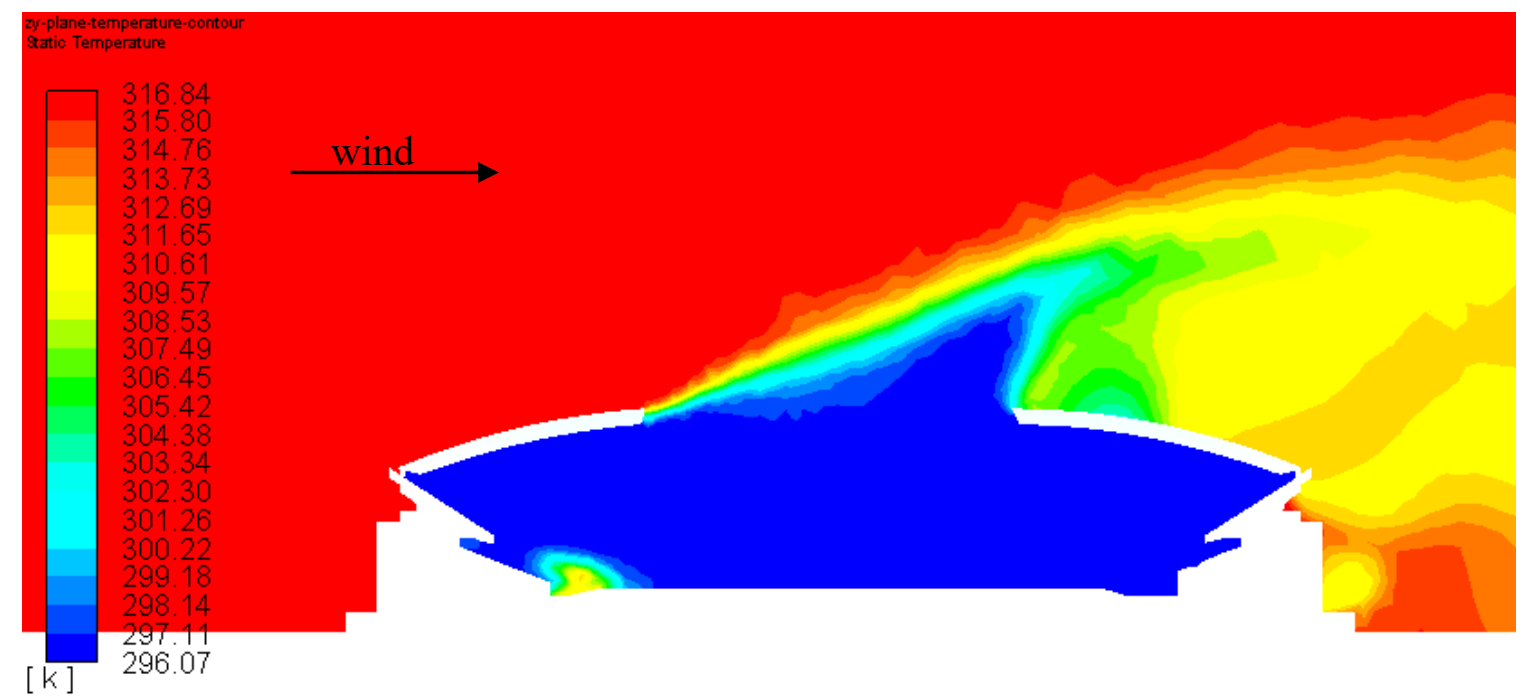

Figure 10. Cross-sectional temperature contour inside the benchmark stadium bowl (left to right wind direction).

Table 3. Some cases that strong wind affected the results of football matches in recent years (Shi \& An 2017).

\begin{tabular}{lccccc} 
Time & Place & \multicolumn{2}{c}{ Both sides } & Beaufort Wind Scale & Results \\
\hline $\mathbf{2 0 1 2 - 0 3 - 0 1}$ & Haifa, Israel & Maccabi Haifa vs Dynamo Kyiv & $\sim 7$ & $13.9-17.1 \mathrm{~m} / \mathrm{s}$ & Resulting own goal \\
\hline $\mathbf{2 0 1 2 - 1 0 - 2 8}$ & Marseille, France & Marseille vs Olympique Lyonnais & $\sim 7$ & $13.9-17.1 \mathrm{~m} / \mathrm{s}$ & Match postponed \\
\hline $\mathbf{2 0 1 4 - 0 2 - 1 3}$ & Manchester, UK & Manchester City vs Sunderland & 7 & $13.9-17.1 \mathrm{~m} / \mathrm{s}$ & Match postponed \\
\hline $\mathbf{2 0 1 4 - 0 2 - 1 3}$ & Liverpool, UK & Everton vs Crystal Palace & 6 & $10.8-13.8 \mathrm{~m} / \mathrm{s}$ & Match postponed \\
\hline
\end{tabular}

In this case, it is evident that the wind velocity inside the stadium bowl doesn't exceed approximately $6 \mathrm{~m} / \mathrm{s}$, with no areas of extreme wind contrast. Therefore, it was concluded that for this design scenario a $10 \mathrm{~m} / \mathrm{s}$ jet inlet velocity was viable. The contour also demonstrates the effectiveness of the Coanda effect, with higher wind velocities experienced underneath the roof. Figure 11 shows the resulting wind velocity contour with a jet inlet velocity of $10 \mathrm{~m} / \mathrm{s}$. 


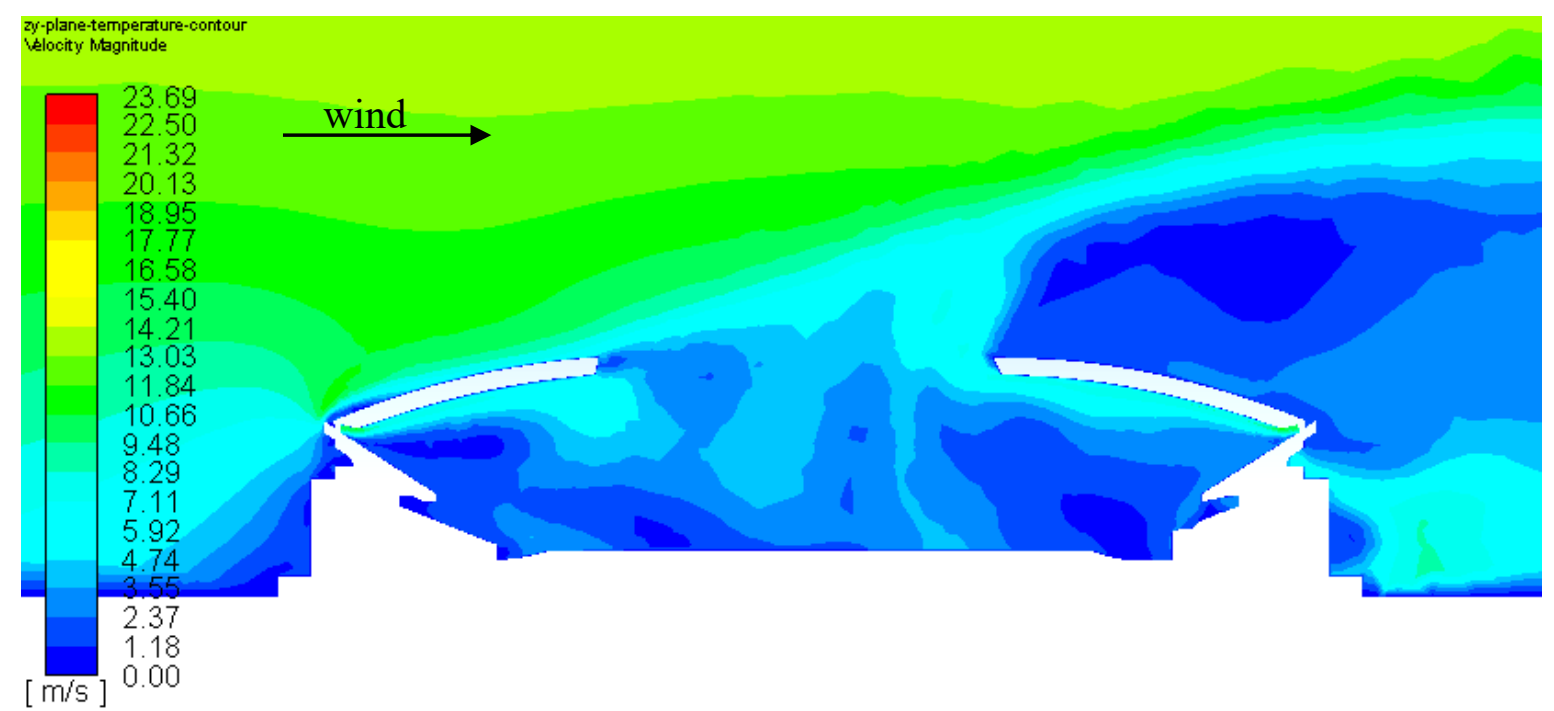

Figure 11. Cross-sectional wind velocity contour inside the stadium bowl (left to right wind direction).

\section{Results and discussions: Closed roof stadium}

As discussed in Sections 2 and 3, a retractable roof offers the potential to create an indoor environment that is much easier to cool due to an increase in the Coanda effect combined with the removal of any possibility of warm air contamination through the roof oculus. Therefore, the roof of the validated model was closed to determine the impact the cooling jets then had on the now-indoor environment. Whilst not relevant to the FIFA 2022 World Cup matches due to the aforementioned legislation (Kennett, 2017), this ensures sufficient operation of the stadium under a closed roof to tackle the legacy issues post-2022. In order to reduce the possibility of error, the previous mesh generation strategy was linked to the new geometry. This ensured absolutely no differences in the process, especially with regards to inflation. The first simulation ran with the updated mesh was repeating the final simulation of an open roof model; Qatar climate conditions and cooling jets in the same location with a $10 \mathrm{~m} / \mathrm{s}$ inlet velocity. The results of this simulation can be seen in Figure 12. 


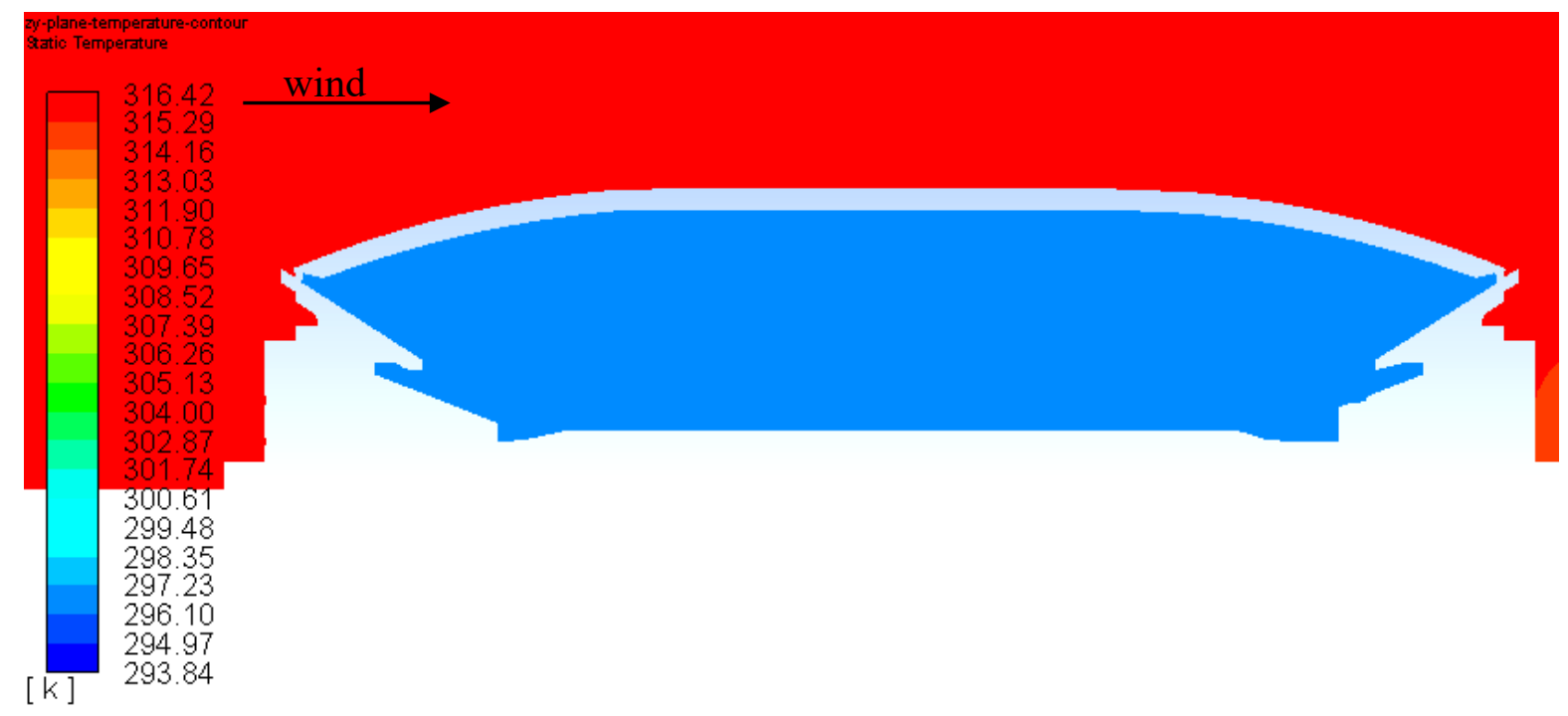

Figure 12. Cross-sectional temperature contour inside the closed roof stadium bowl.

Figure 12 shows how the internal temperature produced is the ideal conditions sought by the present study. The cooling jets resulted in a uniform $23^{\circ} \mathrm{C}$ internal temperature despite the $43.2^{\circ} \mathrm{C}$ external temperature, and the closing of the roof oculus kept the cool air circulating around the stadium bowl, preventing the influx of hot air through the ventilation openings. However, it was also observed that the wind velocities were excessive inside the stadium bowl. In an attempt to reduce the internal wind velocities experienced, the cooling jet inlet velocity was reduced to $5 \mathrm{~m} / \mathrm{s}$. Despite the reduction in jet inlet velocity, the desired internal temperature of $23^{\circ} \mathrm{C}$ was still observed, with the same uniform distribution as recorded for the $10 \mathrm{~m} / \mathrm{s}$ inlet velocity. Additionally, the wind velocities have been drastically reduced. The lower inlet velocity has subsequently decreased the experienced velocity to below $10 \mathrm{~m} / \mathrm{s}$ above the pitch. The one drawback, however, is the high wind velocities experienced below the upper tier of the terraces. The wind velocities here exceeded $20 \mathrm{~m} / \mathrm{s}$ and would cause significant discomfort to spectators. As with the previous closed-roof simulations, a reduction of the cooling jet inlet velocity to $2.5 \mathrm{~m} / \mathrm{s}$ still resulted in a constant $23^{\circ} \mathrm{C}$ internal temperature. However, the presence of the region of high wind velocity underneath the upper tier of the terraces 
was still observed. Additionally, the ventilation openings were beginning to impact the internal environment with regards to wind velocity, and hence an alternative solution required investigation.

\section{Results and discussions: Alternative roof stadium}

Before modifying the roof structure, additional literature review was conducted in an effort to determine the most effective adaptations, namely either increasing or decreasing the pitch of the roof. Table 3 was an extract from a study (Shi \& An, 2017) that subsequently produced Table 4 showing the relationship between roof geometry and wind velocity.

Table 4. The brief results for canopy section profile (Shi \& An, 2017).

\begin{tabular}{cccc} 
& Distribution uniformity & Maintaining stability & Reducing wind speed (Windy \\
& & & areas) \\
\hline Upward canopy & Better & Poor & Poor \\
\hline Flat canopy & Moderate & Moderate & Moderate \\
\hline $\begin{array}{c}\text { Downward } \\
\text { canopy }\end{array}$ & Poor & Better & Better \\
\hline
\end{tabular}

Considering the findings of Table 4 , the roof of the stadium model was modified to start as a flat canopy and then curve downward, as indicated in Figure 19. This was an effort to utilise the most effective solution to reducing the wind velocity whilst balancing between optimal distribution uniformity and maintaining stability.

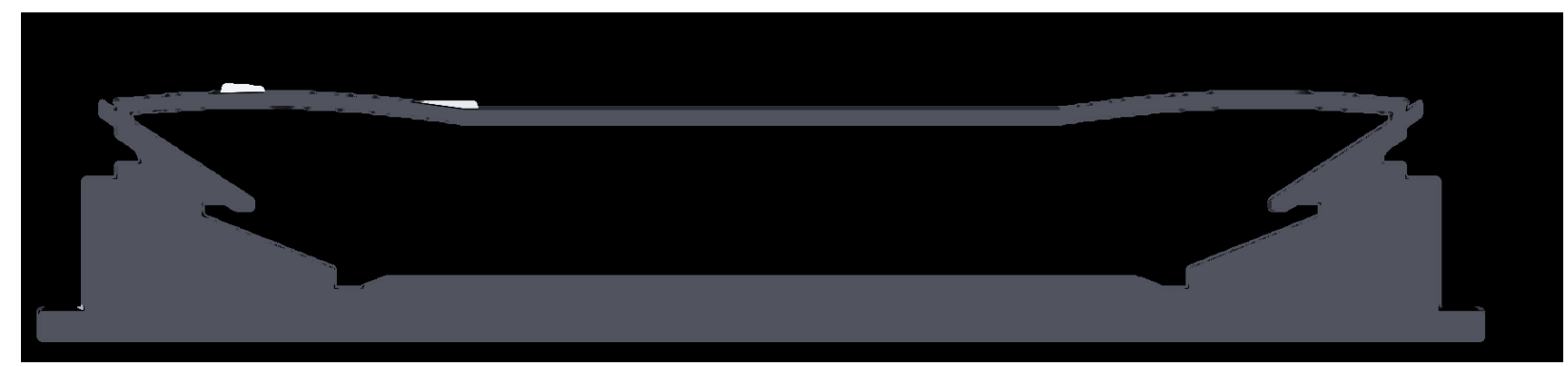

Figure 13. Downward roof stadium cross-section.

Figure 21 shows how the wind velocity inside the stadium bowl was reduced to 
desirable conditions while a constant internal temperature of $23^{\circ} \mathrm{C}$ was observed. The velocity experienced on the pitch remains consistently under $5 \mathrm{~m} / \mathrm{s}$ with no severe gradient, and the hot spot below the upper terraces has been reduced. A small hot spot occurs around the northern opening. Based off one simulation, the conclusions drawn in (Shi \& An, 2017) appeared correct. In an effort to remove the hot spot, the cooling jet inlet velocity was reduced to $2.5 \mathrm{~m} / \mathrm{s}$.

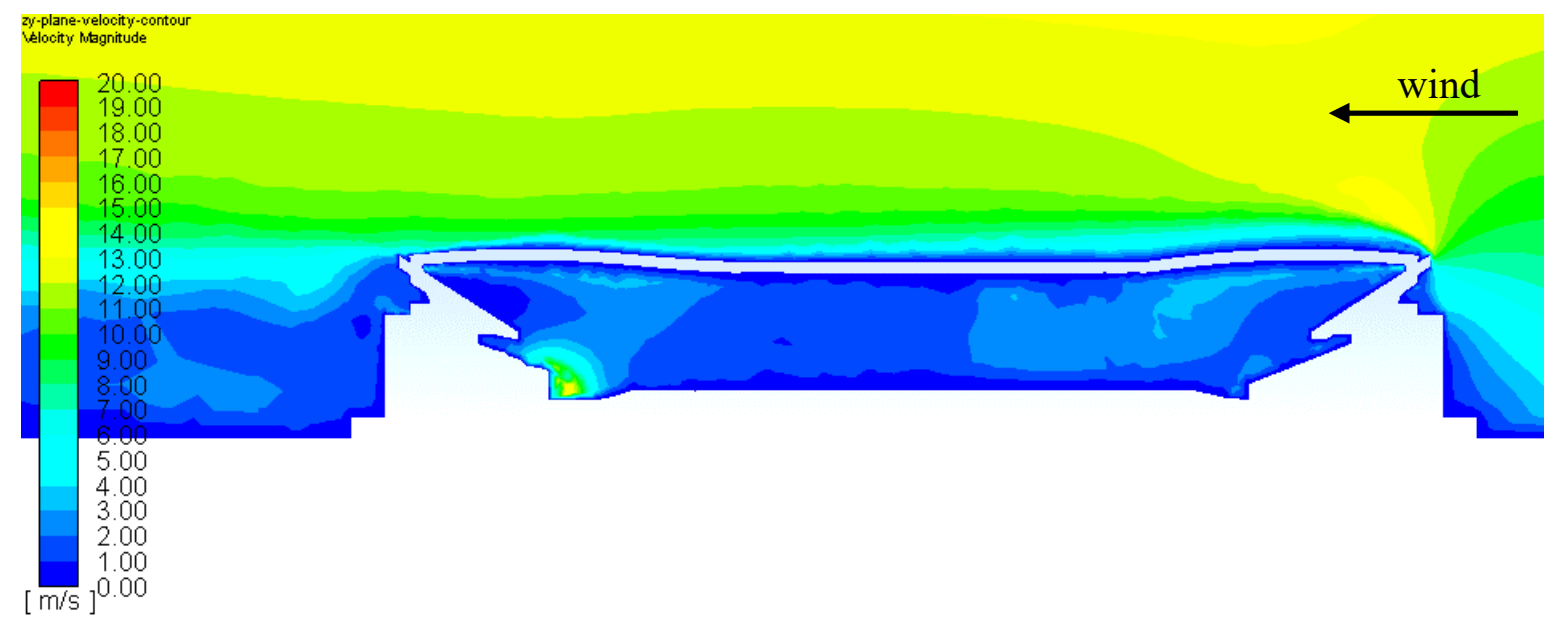

Figure 14. Cross-sectional wind velocity contour inside the closed, downwards curved roof stadium bowl (left to right wind direction).

As with the Section 5 , a $2.5 \mathrm{~m} / \mathrm{s}$ inlet velocity was expected to provide sufficient cooling to a $23^{\circ} \mathrm{C}$ internal temperature and reduce the wind velocity experienced inside the stadium bowl. This hypothesis was correct, with a constant $23^{\circ} \mathrm{C}$ internal temperature experienced combined with wind velocities shown in Figure 15. 


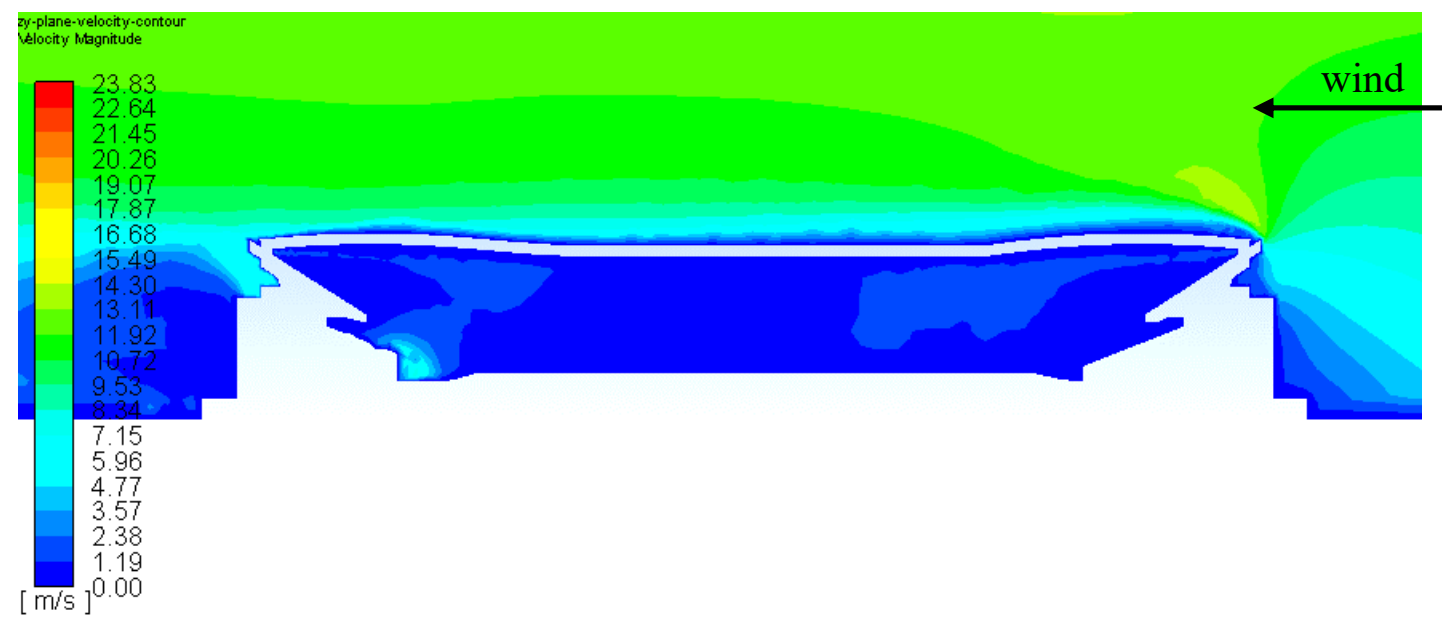

Figure 15. Cross-sectional wind velocity contour inside the closed, downwards curved roof stadium bowl (left to right wind direction).

Figure 15 exhibited the improvement in the recorded wind velocities inside the stadium bowl expected; a maximum velocity of approximately $4 \mathrm{~m} / \mathrm{s}$, very little velocity gradient and a severe reduction in the magnitude of the hot spot at the ventilation opening. It was concluded, therefore, that a $2.5 \mathrm{~m} / \mathrm{s}$ inlet velocity combined with a closed, downward roof produced desirable conditions to facilitate regular matches even in the extreme design temperatures of the Qatari summer. However, as previously discussed, legislation (Kennett, 2017) dictates an open roof for FIFA World Cup matches, hence additional simulations were necessary to model the retracted roof.

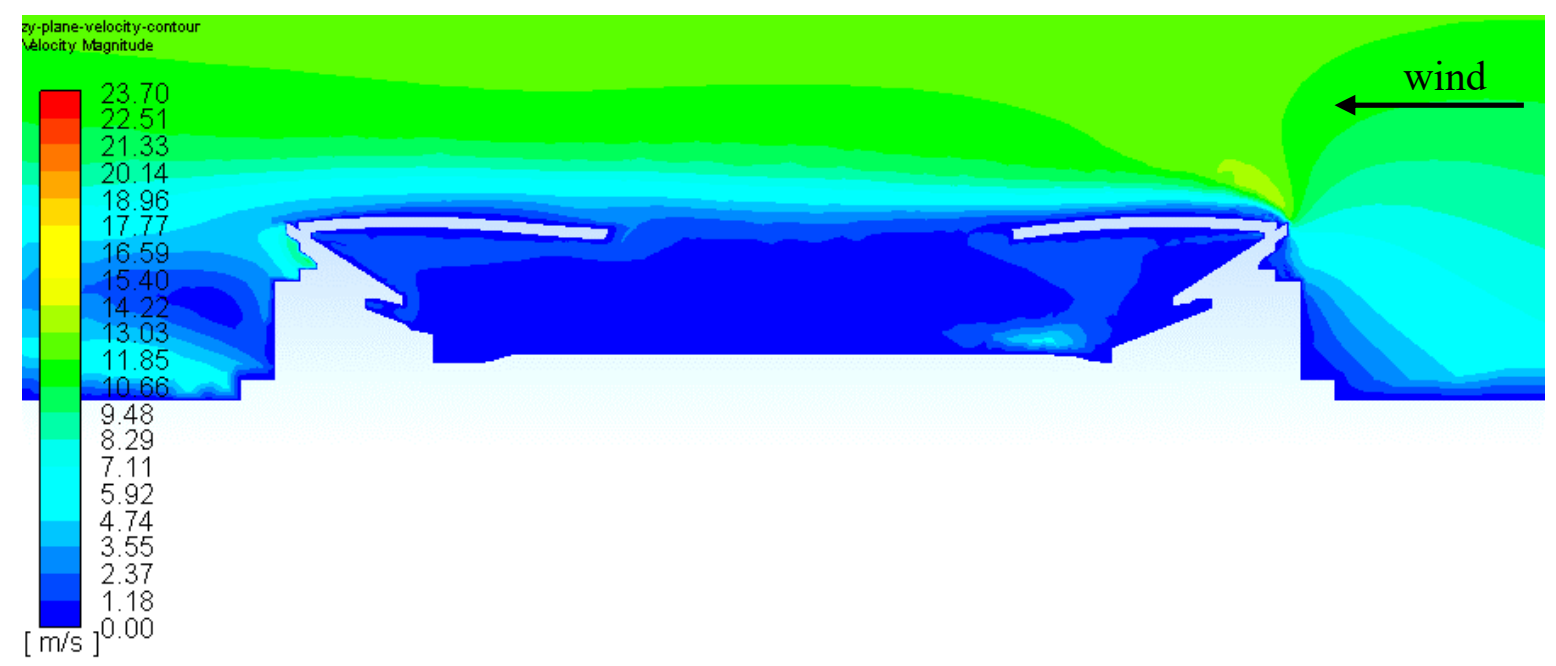


Figure 16. Cross-sectional wind velocity contour inside the open, downwards curved roof stadium bowl $(2.5 \mathrm{~m} / \mathrm{s}$ inlet velocity) (left to right wind direction).

Reversing the process outlined in Section 5 in conjunction with a $2.5 \mathrm{~m} / \mathrm{s}$ inlet velocity produced Figure 16. The largest concern with an open, downwards curved roof was the potential encouragement of hot wind flowing into the roof oculus stimulated by the roof shape. Figure 16, however, shows that the external air isn't driven into the stadium bowl despite the roof geometry. Contrarily, the wind velocities experienced inside the stadium bowl are uniform and insubstantial. It could be argued that Figure 16 displays the most optimal wind conditions of any previous simulation conducted. Therefore, the temperature distribution was the only other factor obstructing the downward, open roof from complete usability in all conditions. The resulting temperature contour is shown in Figure 17.

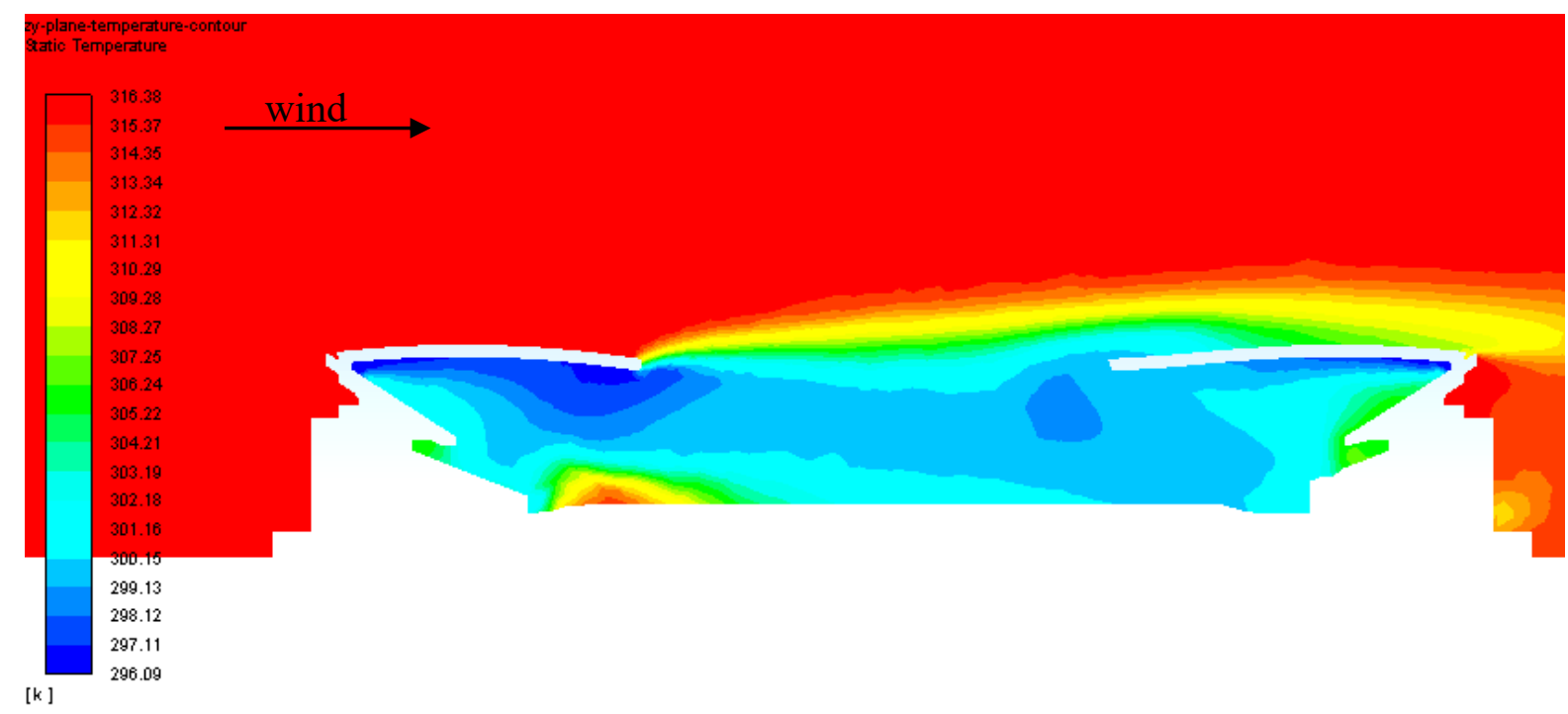

Figure 17. Cross-sectional temperature contour inside the stadium bowl $(2.5 \mathrm{~m} / \mathrm{s}$ inlet velocity) (left to right wind direction).

The customary temperature hot spot around the ventilation opening was once again present; a condition created by each open-roof simulation. Despite the competent temperature distribution elsewhere inside the stadium bowl, the presence of this hotspot 
and the warmer-than-desired regions in the terraces suggested that additional cooling would be required. Learning from the results of the previous open-roof simulations, increasing the cooling jet inlet velocity had little effect on the wind velocities experienced inside the stadium bowl. Therefore, using a $10 \mathrm{~m} / \mathrm{s}$ jet inlet velocity as in Section 4 yielded results as shown in Figure 18.

Despite the marginal impact of the external air through the roof oculus, the overwhelming experienced temperature inside the stadium bowl is the desired $23^{\circ} \mathrm{C}$; a clear improvement from the previous configuration. However, the northern ventilation opening hotspot once again occurred, alongside a small, unwanted temperature increase underneath the upper terrace. To show that the aforementioned hypothesis that the inlet velocity has little effect on the experienced wind velocity, the contour is presented in Figure 19. An increase in wind velocity was observed, however the small gradient and $<7 \mathrm{~m} / \mathrm{s}$ magnitude suggested a satisfactory airflow distribution.

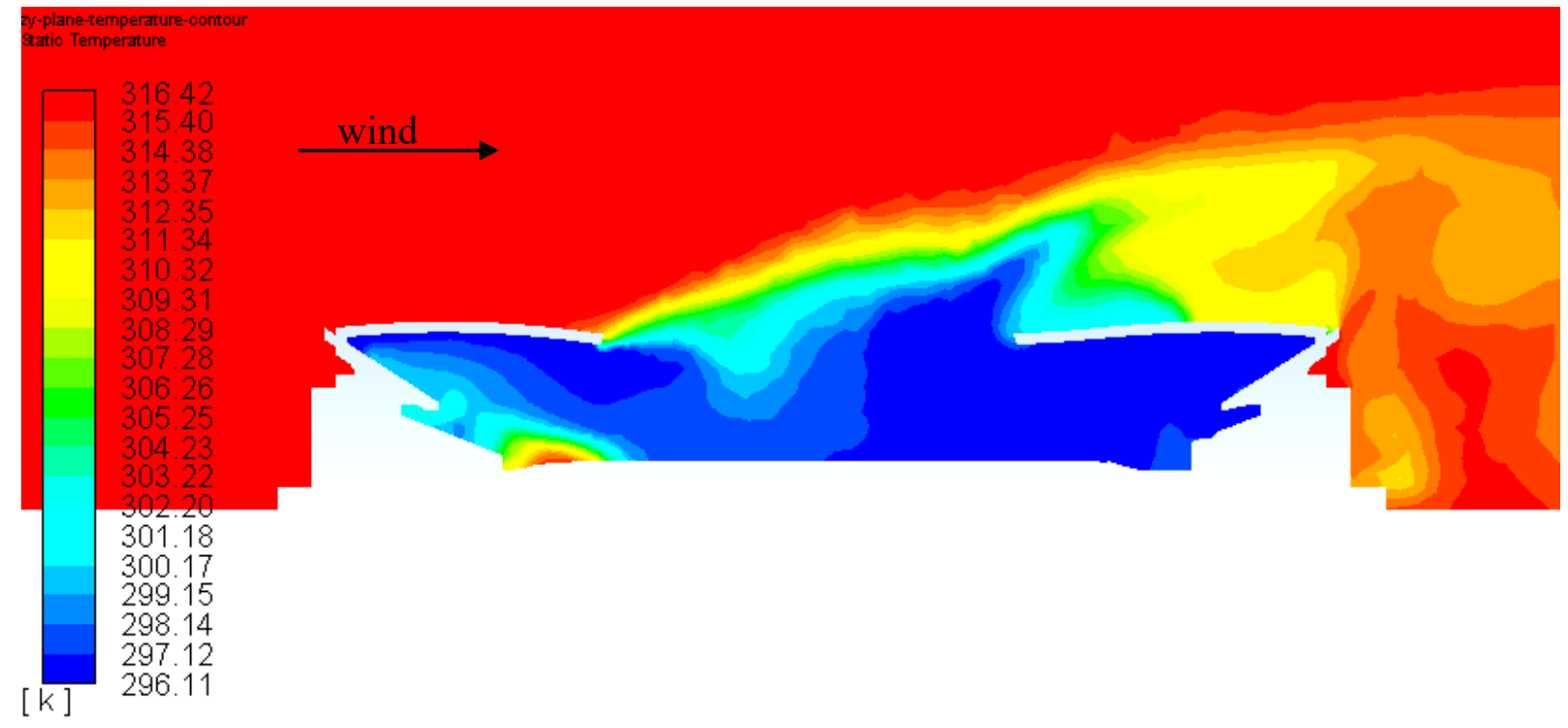

Figure 18. Temperature contour inside the stadium bowl $(10 \mathrm{~m} / \mathrm{s}$ inlet velocity) (left to right wind direction). 


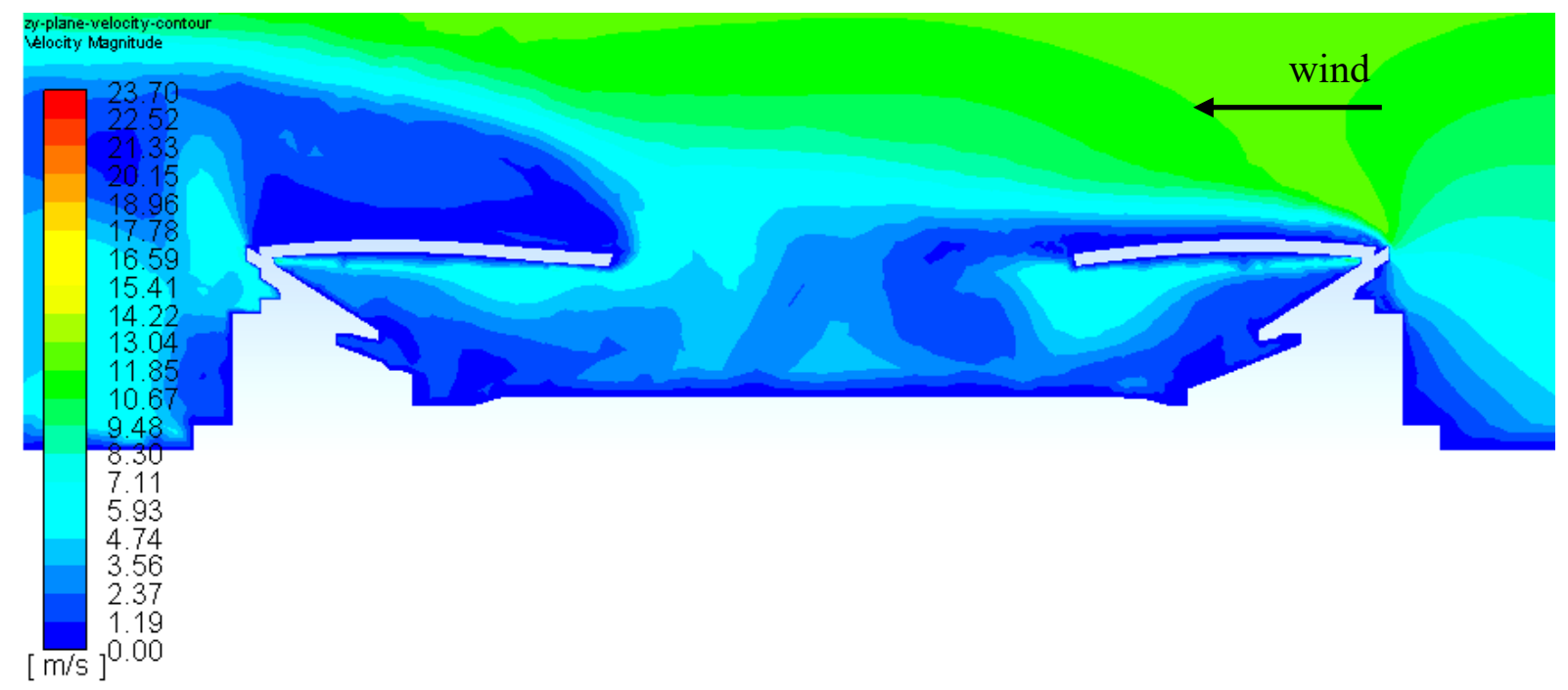

Figure 19 . Wind velocity contour inside the stadium bowl $(10 \mathrm{~m} / \mathrm{s}$ inlet velocity) (right to left wind direction).

\section{Conclusions and recommendations for further research}

The primary focus of the present study was to improve the legacy of the 2022 FIFA World Cup through the modelling of wind and thermal flow patterns in various stadium designs. This stemmed from an absence of existing literature focussing on thermal flow in hot and humid or dry conditions for stadia. The work highlighted the use of CFD, along with the existing environmental conditions and necessary model validation, to investigate the effects of open and closed, upward-curved and downward-curved roof geometries in an effort to produce an adequate interior temperature whilst minimising wind velocities. If all cases were to be utilised during occupation then a closed, downward roof geometry yielded the most satisfactory conditions. Backed by literature (Shi \& An 2017), the shape combined with a $2.5 \mathrm{~m} / \mathrm{s}$ cooling jet inlet resulted in a limited magnitude of wind velocities inside the stadium and an adequate operating temperature; never exceeding approximately $6 \mathrm{~m} / \mathrm{s}$ with a near-constant $4 \mathrm{~m} / \mathrm{s}$ experienced in vital areas, and a successfully cooled interior environment of $23^{\circ} \mathrm{C}$.

However, with legislation (Kennett, 2017) dictating a roof oculus opening present 
during FIFA World Cup matches the closed, downward roof geometry would only suffice as a method of preconditioning the stadium bowl. Before spectator entrance, the roof must be retracted to open up the pitch to the external environment. To counteract the additional solar gains, alongside the potential for hot wind to enter the stadium bowl through the new opening, the cooling jet inlet velocity must be increased to $10 \mathrm{~m} / \mathrm{s}$, with the simulation results showing little disruption to the playing conditions as a result of increased jet velocity. It was evident that the wind velocity inside the stadium bowl doesn't exceed approximately $6 \mathrm{~m} / \mathrm{s}$, with no areas of extreme wind contrast. Therefore, it was concluded that for this design scenario a $10 \mathrm{~m} / \mathrm{s}$ jet inlet velocity was viable. The internal temperature, however, suffered as a result of opening the roof oculus. This occurred in every open-roof simulation, and so minimising the effect would be the chief task of any supplementary research.

The primary risk associated with the downward roof geometry was the potential weight of a retractable roof. Additional support, through either an arch similar to Wembley Stadium, stanchions inside the stadium or an exoskeleton around the stadium already present with the Amsterdam ArenA would be required. With the lack of external wind impacting the stadium bowl in any design scenario, either the arch or exoskeleton structures would be preferable to reduce the impact on spectators. Additionally, the introduction of an aesthetic structure would improve the legacy of the tournament through the creation of a visual attraction, as was the case with Wembley Stadium.

The conclusions drawn from the present study offer potential areas of further research and simulation. Improved computational power could create a transient model of an open-roof scenario to show how the preconditioned stadium bowl adapts with the introduction of external air in an effort to ensure spectator satisfaction throughout the match. This could be simulated in conjunction with closing the ventilation openings 
following the spectator entrance to attempt to prevent the hotspot of hot air occurring around the northern ventilation opening. Another area could be the research into the introduction of renewable energy solutions to subsidise the high cooling load that would occur with the implementation of the design scenarios in the present study. Other parameters could be made the primary focus; the humidity and solar radiation levels would both exceed the required conditions for elite-level performance due to the climate. Additionally, each parameter could be further investigated by utilising experimental methods including scaled wind tunnel testing and field or real site testing. The data obtained would be useful to validate the modelling carried out in the present work.

\section{Acknowledgments}

The authors would like to thank the support of the Department of Architecture and Built Environment for providing the facility for carrying out the modelling and simulations.

\section{Nomenclature}

$\begin{array}{lll}A C H & \text { Air changes per hour } & \left(\mathrm{h}^{-1}\right) \\ \varepsilon & \text { Turbulence dissipation rate } & (\mathrm{J} / \mathrm{kg} . \mathrm{s}) \\ \mathrm{h} & \text { Height } & (\mathrm{m}) \\ I_{u} & \text { Turbulent intensity } & (\%) \\ \mathrm{L} & \text { Length } & (\mathrm{m}) \\ k & \text { Turbulent kinetic energy } & (\mathrm{J} / \mathrm{kg}) \\ K & \text { von Karman constant } & \text { Dimensionless } \\ \dot{Q} & \text { Volumetric flow rate } & \left(\mathrm{m}^{3} / \mathrm{s}\right) \\ \mathrm{U} & \text { Wind velocity } & (\mathrm{m} / \mathrm{s}) \\ \mathrm{U}_{\mathrm{ABL}}{ }^{*} & \text { Atmospheric boundary layer friction velocity } & (\mathrm{m} / \mathrm{s}) \\ \mathrm{U}_{10} & \text { Reference wind velocity at } 10 \mathrm{~m} & (\mathrm{~m} / \mathrm{s}) \\ \mathrm{V} & \text { Stadium model volume } & \left(\mathrm{m}^{3}\right) \\ \mathrm{W} & \text { Width } & (\mathrm{m})\end{array}$




\section{References}

ASHRAE Handbook - Fundamentals (SI). (2005). Atlanta, GA.: The American Society of Heating, Refrigerating and Air-Conditioning Engineers, Design conditions for DOHA INTL AIRPORT, Qatar.

Arup Associates (2017). Qatar Showcase :: ARUP ASSOCIATES. Available at: http://www.arupassociates.com/en/case-studies/qatar-showcase/

Beaard, R. (2013). FIFA heat policy insufficient - FIFPro World Players' Union. FIFPro World Players' Union. Available at: https://www.fifpro.org/news/fifa-heat-policyinsufficient-2/en/

Blocken, B., Stathopoulos, T. \& Carmeliet, J. (2007). CFD simulation of the atmospheric boundary layer: wall function problems. Atmospheric Environment, 41(2), 238-252.

Calautit, J.K. \& Hughes, B.R. (2014a). Measurement and prediction of the indoor airflow in a room ventilated with a commercial wind tower. Energy and Buildings, Volume 84, 2014, 367-377.

Calautit, J.K. \& Hughes, B.R. (2014b). Wind tunnel and CFD study of the natural ventilation performance of a commercial multi-directional wind tower, Building and Environment. 80, 71-83.

Calautit, J., Hughes, B.R. \& Nasir, D. (2017). Climatic analysis of a passive cooling technology for the built environment in hot countries. Applied Energy, 186, 321-335.

Chaudhry, H., Calautit, J.K. \& Hughes, B.R. (2015). Computational analysis of a wind tower assisted passive cooling technology for the built environment. Journal of Building Engineering, 1, 63-7.

Cook, M. J., Ji, Y. \& Hunt, G. R. (2003) CFD Modelling of Natural Ventilation: Combined Wind and Buoyancy Forces, International Journal of Ventilation, 1:3, 169179

Cowan, I.R., Castro, I.P. \& Robins, A.G. (1997). Numerical considerations for simulations of flow and dispersion around buildings. Journal of Wind Engineering and Industrial Aerodynamics, Vol. 67 \& 68, 535-545.

FIFA.com. (2017). FIFA Executive Committee confirms November/December event period for Qatar 2022. Available at:

https://www.fifa.com/worldcup/qatar2022/news/y=2015/m=3/news=fifa-executivecommittee-confirms-november-december-event-period-for-q-2567789.html

Ghani, S., Bialy, E., Bakochristou, F., Gamaledin, S., Rashwan M. \& Hughes, B. (2017). Thermal comfort investigation of an outdoor air-conditioned area in a hot and arid environment. Science and Technology for the Built Environment, 23, 1113-1131. 
Gong, J. \& Hang, J. (2018) Buoyancy-driven natural ventilation in one storey connected with an atrium, International Journal of

Ventilation, DOI: 10.1080/14733315.2018.1524195

Jiang, Y., Allocca, C., \& Chen, Q. (2004) Validation of CFD Simulations for Natural Ventilation, International Journal of Ventilation, 2:4, 359-369

Jiru, T. \& Bitsuamlak, G. (2010) Application of CFD in Modelling Wind-Induced Natural Ventilation of Buildings - A Review, International Journal of Ventilation, 9:2, 131-147

Kennett, S. (2017). Qatar's zero carbon stadium: 96 degrees in the shade. Building. Available at: https://www.building.co.uk/buildings/qatars-zero-carbon-stadium-96degrees-in-the-shade/5008557.article

Lechowska, A. \& Schnotale, J. (2015). The window edge-of-glass region temperature profile improvement by inserting a small additional glass pane - a CFD study and measurements. Journal of Building Engineering, 4, 41-51.

Lee, S., Park, B., Kim, J. \& Kato, S. (2016). Evaluation of thermal characteristics on a multi-sheet-type radiant panel heating system, Journal of Building Engineering, 8, 4857.

Mochida, A., Tominaga, Y., Murakami, S., Yoshie, R., Ishihara, T. \& Ooka, R. (2002). Comparison of various k- models and DSM to flow around a high rise building - report of AIJ cooperative project for CFD prediction of wind environment. Wind \& Structures, $5,227-244$

Moosavi, L., Zandi, M. \& Bidi, M. (2018). Experimental study on the cooling performance of solar-assisted natural ventilation in a large building in a warm and humid climate. Journal of Building Engineering, 19, 228-241.

Richards, P.J. \& Hoxey, R.P. (1993). Appropriate boundary conditions for computational wind engineering models using the k- $\varepsilon$ turbulence model. Journal of Wind Engineering and Industrial Aerodynamics, 46 \& 47, 145-153.

Shi, L. \& An, R. (2017). An Optimization design Approach of Football Stadium Canopy Forms Based On Field Wind Environment Simulation. Energy Procedia, 134, 757-767.

Sofotasiou, P., Hughes, B. \& Calautit, J. (2015). Qatar 2022: Facing the FIFA World Cup climatic and legacy challenges. Sustainable Cities and Societies, 14, 16-30

Sofotasiou, P., Hughes, B. \& Ghani, S. (2017). CFD optimisation of a stadium roof geometry: a qualitative study to improve the wind microenvironment. Sustainable Buildings, 2, 19.

Tominaga, Y., Mochida, A., Yoshie, R., Kataoka, H., Nozu, T., Yoshikawa, M. \& Shirasawa, T. (2008) AIJ guidelines for practical applications of CFD to pedestrian wind environment around buildings, Journal of Wind Engineering and Industrial Aerodynamics, 96, 1749-1761. 
Van Hooff, T. \& Blocken, B. (2010a). Coupled urban wind flow and indoor natural ventilation modelling on a high-resolution grid: A case study for the Amsterdam ArenA stadium. Environmental Modelling \& Software, 25(1), 51-65.

Van Hooff, T. \& Blocken, B. (2010b). On the effect of wind direction and urban surroundings on natural ventilation of a large semi-enclosed stadium. Computers \& Fluids, 39(7), 1146-1155.

Van Hooff, T. \& Blocken, B. (2013). CFD evaluation of natural ventilation of indoor environments by the concentration decay method: $\mathrm{CO} 2$ gas dispersion from a semienclosed stadium. Building and Environment, 61, 1-17.

Web Archive. (2009). FIFA.com - Combined bidding confirmed. Available at: https://web.archive.org/web/20090122070321/http://www.fifa.com/aboutfifa/federation/ bodies/media/newsid\%3D983481.html

Yao, R., Costanzo, V., Li, X., Zhang, Q. \& Li, B. (2018). The effect of passive measures on thermal comfort and energy conservation. A case study of the hot summer and cold winter climate in the Yangtze River region. Journal of Building Engineering, $15,298-310$. 